\title{
AGRICULTURAL IMPACTS ON GROUNDWATER: PROCESSES, MODELLING AND DECISION SUPPORT ${ }^{1}$
}

\author{
Andrea Giacomelli*, Carlo Giupponi** and Claudio Paniconi* \\ *CRS4 (Center for Advanced Studies, Research and Development in Sardinia), Cagliari, Italy \\ **Dipartimento di Agronomia Ambientale e Produzioni Vegetali Università degli Studi di Padova \\ and Fondazione ENI Enrico Mattei
}

\section{INTRODUCTION}

Agriculture, like other economic activities, can have negative impacts on the environment and on groundwater in particular, with consequences for human health as well as the environment ( $F A O$, 1979; 1996). On the one hand the use of groundwater by agriculture can cause quantitative resource depletion and qualitative deterioration due to overuse or misuse, such as encroaching saltwater and salinisation in coastal areas. On the other hand, the recharge of aquifers with water leached out from cultivated fields can lead to water pollution by agro-chemicals (fertilisers and pesticides). Indeed, of the many types of compounds that can contaminate soils and groundwaters, those most closely associated with agricultural practices, and whose impacts will be discussed in depth in this contribution, are nutrients, pesticides, and salt.

Once contaminants enter the subsurface, they are subject to complex physical, biological, and chemical processes that transport and transform them. Accurate monitoring, together with mathematical models capable of realistically representing these processes, can be useful tools for studying the behaviour and effects of contaminants in subsurface waters. The models can be used for predicting future migration and for assessing alternative remediation strategies, and can provide information useful to the "decision maker" responsible for monitoring and planning resource utilisation and for devising improved water resource management practices. An understanding of the fundamental processes that control the fate and transport of subsurface pollutants is critical to the development of simulation models for the prediction and analysis of these phenomena. The most comprehensive models are those constructed using so-called process- or physically-based approaches, although in many cases and for various reasons more empirical or conceptual models are used as well.

There is a wealth of concepts and issues connected to the modelling of natural phenomena and to the effective use (or, just as commonly, subtle abuse) of models. These range from the difficulties in handling inherent variability, scale, and nonlinearity to the need for effective pre- and postprocessing of model inputs and outputs, transforming simulation results to "useful" information. We dwell in particular on the latter issue, which we feel:

- goes beyond mathematical-physical aspects to touch on current and emerging issues related to the practical application and integration of models with agricultural and environmental policy;

\footnotetext{
1 ) In this report the authors made the following contributions: A. Giacomelli GIS aspects; C. Giupponi agrienvironmental science and decision support; C. Paniconi hydrology and modelling. A. Giacomelli and C. Paniconi acknowledge the partial financial support of the Regione Autonoma Sardegna.
} 
- is relevant to general efforts to bridge the gaps between the study of natural phenomena and the analysis and implementation of socio-economic policies;

- can contribute to the definition of mutually compatible agricultural and water management policies;

- brings together field work and experimental activities with simulation models and other advances in information technology such as geographic information systems (GIS) and remote sensing - all essential elements in the evolution of decision support systems that aim to contribute to more effective environmental monitoring and resource management.

This contribution deals in general with the assessment of agricultural production processes in relation to the environment, with specific emphasis given to groundwater resources in southern European countries and the Mediterranean. We will describe these production processes, their relation to and impact on groundwater, and the basic mechanisms and dynamics involved in the flow of water and transport of contaminants in soil and aquifer systems. An example of different modelling approaches is given, and the limitations and advantages of various approaches are discussed.

\section{GENERAL CONCEPTS}

\section{Pollution from agricultural sources}

Agricultural activities always have significant effects on the environment; some of these effects are positive, others are negative. Among the latter are the phenomena of degradation of water resources identified as pollution from agricultural sources, PFAS $(E C, 1991)$. PFAS can be defined as a series of possible negative changes to the state of environmental variables (qualitative or quantitative) due to the introduction of substances or techniques used in primary production in the agro-ecosystem. Typical examples are the appearance of herbicides in groundwater as a consequence of weed control, or the rise in nutrient concentrations in runoff waters caused by fertilisation. In general, the main cause of these phenomena is that the efficiency of agricultural production processes never reaches $100 \%$ and, more importantly, tends to decrease with the intensity of agricultural production systems.

Apart from those pollution phenomena deriving from intensive livestock rearing that produce wastes (liquid manure in particular) that could be described as point sources, the emissions of pollutants from agricultural fields are in general defined as diffuse (or non-point) sources (Novotny and Olem, 1994). These are characterised by the fact that they introduce polluting substances into the environment over wide areas in a spatially distributed way (i.e. with variations depending on the location), at irregular temporal intervals and under the effects of interactions between anthropic and natural variables. The hydrologic cycle is the main engine of these phenomena (Figure 1) and water is generally both the vector of pollutants and the receptor of impacts.

Two main categories of pollutants should be dealt with in examining the pollution of groundwater from agricultural sources: nutrients and pesticides. Nutrients are mineral or organic compounds containing nitrogen, phosphorus or potassium that occur in soils and water through natural processes (animal manure, microbial breakdown of organic matter) and through human activities or human-controlled land use practices (application of fertilisers, sewage releases, soil cultivation, livestock production). In dissolved form, the principal nutrient-derived pollutants are nitrate $\left(\mathrm{NO}_{3}\right)$, ammonium $\left(\mathrm{NH}_{4}\right)$, and phosphate $\left(\mathrm{PO}_{4}\right)$. Nutrients pose risks to both human health (e.g. "blue baby" syndrome caused by drinking rich in nitrates) and aquatic ecosystems (e.g. eutrophication of surface waters due to phosphates). Pesticides are synthetic organic compounds used to controls weeds, insects, and other organisms, and their presence in groundwater is exclusively 
anthropogenic. At high concentrations in drinking water pesticides can pose serious risks to human health; similar risks can derive to non-mammal biota (e.g. fish) in freshwaters.

Releases of fertilisers and pesticides can be referred to as a direct impact of agriculture on groundwater, in the sense that the contaminants are directly introduced into the environment as agricultural inputs.

\section{Salinisation and seawater intrusion}

Salt is found naturally in seas and in geologic formations (salt domes in sedimentary basins, for example), and can be introduced artificially as a by product of fertilisers or land-disposed wastes. Even the digging of wells can in some cases destruct natural barriers (e.g., impermeable layers) and put freshwaters in communication with saline ones (Atkinson, 1987). Because it is so widespread, salt constitutes a particularly important category of groundwater pollutant, occurring in groundwater and soils via seawater intrusion or other salinisation processes. Saltwater is not considered a health risk per se, but its presence in soils or underground waters used for industrial, agricultural, or domestic purposes can have grave economic consequences. In coastal aquifers, prolonged overpumping of groundwater can lead to an encroachment of the interface between seawater and freshwater, through intrusion and/or upconing (Sherif and Singh, 1996; Bear et al., 1999).

If the aquifer is overexploited for irrigation water, then the resulting intrusion or upconing is referred to as an indirect impact of agriculture on groundwater, in the sense that the contamination is not directly introduced as an agricultural input (as with nutrients or pesticides), but rather is induced by extracting too much water to satisfy irrigation needs.

\section{Resource depletion and sustainable agriculture}

Considering the conflicts between agriculture and the environment (soil loss by erosion, water pollution, salinisation, etc.), especially in relatively dry areas such as southern Europe and the Mediterranean, many authors treat these pheonomena within the broader concept of desertification. Desertification can, in fact, be considered as a complex phenomenon determining reductions of biological and economic productivity and increased pollution (Perez-Trejo, 1992). In this regard water is obviously a crucial natural resource, and the Mediterranean is one of the areas where such conflicts are particularly felt.

The intensity of agricultural impacts on groundwater is determined by a combination of abiotic (climate, geomorphology, etc), biotic (vegetation and fauna), and merobiotic (soil) factors. When performing an environmental impact assessment of an agricultural system it is therefore important to consider the territorial context of implementation. The compatibility, or inversely the conflict, of

a production system with the environment is a function of the interactions between its environmental pressures and the vulnerability of the land. For the purposes of the present work, it is useful to consider these aspects (impacts, compatibility, vulnerability, etc) within the broader concept of sustainability. Following the FAO definition of sustainable agricultural development (FAO, 1996), the perspective adopted herein is to contribute to the identification of agricultural activities able to manage and conserve groundwater resources and to direct technological and institutional changes, ensuring the satisfaction of society's present and future water needs.

\section{Basic territorial units: hillslope, aquifer, and watershed}

The hillslope, the catchment (or watershed), and the aquifer are the commonest territorial units used in studies dealing with the hydrological cycle (Figure 1) and associated processes such as transport of solutes in natural porous media. One of the most important distinctions to be made, applicable to all three units, is that between the unsaturated zone, variously called the soil or vadose zone, where the pores contain air and water, and the saturated or groundwater zone, where only water is present. 
The two zones are separated by the water table. The water table rises and falls, and the degree of saturation in the vadose zone increases and decreases, in response to rainfall, evaporation, groundwater pumping, irrigation, and other external forcing variables.

The nature of these fluctuations in response to natural atmospheric forcing, and the degree to which the subsurface can act as "buffer" and "filter", is illustrated in Figure 2, where the propagation of a rainfall signal, which is highly variable, is dampened (and also shifted in time) as it passes through successive "storage" components associated with the surface (runoff), near-surface (soil moisture), water table, and deep subsurface (groundwater). An anomalous event (excessive rainfall leading to flooding, extended dry period leading to drought, a major contaminant spill on the surface) can be identified and monitored in different ways across these various layers of the subsurface as the dominant signal and surrounding noise are attenuated and smoothed out.

The hillslope is the smallest of the basic units, with a typical length of hundreds of meters and a depth on the order of meters. It is an ideal unit for conducting field trials and for obtaining ground measurements relating to processes such as percolation, seepage, flow through macropores, and the exchanges of water and energy between the soil, root zone, surface vegetation, and atmosphere. One and two-dimensional models are often adequate for hillslope scale studies.

An aquifer system can contain a number of stratified aquifers separated by less permeable geologic units such as aquitards and aquicludes. An individual aquifer can be unconfined (in contact with the unsaturated zone) or confined, and can range in scale from local units of modest depth and extent to regional scale aquifers deep below the surface of the Earth.

The watershed is the fundamental unit used in many branches of hydrologic research such as studies of land-atmosphere interactions for climate change, flood frequency analysis for extreme events, and sediment transport and erosion in geomorphology. A watershed connects the atmosphere, land surface, subsurface, and streams, and is a conduit for the endless transformation and transportation of energy, water, solutes, and sediments. It constitutes a self-contained hydrologic unit in the sense that it has a natural topographic boundary separating it from surrounding catchments and a natural outlet - a particle of water that falls on its surface cannot flow (overland) beyond this boundary, and any water that does not evaporate or percolate to deep aquifers eventually reaches the outlet, either via overland or subsurface routes. Increasingly, point and nonpoint source water pollution problems are being addressed at the watershed scale, along with more generic water management issues, as is made explicit in the recent Water Framework Directive of the European Commission (EC, 1999). The emergence of the catchment as a reference unit in water directives is aided by the widespread availability of digital terrain data and GIS-based topographic analysis software (Band, 1986; Jenson and Domingue, 1988), with which a watershed's boundaries can be delineated, its stream network identified, and its area subdivided into smaller and still hydrologically distinct units, from subcatchments right down to hillslopes. Watersheds can range in size from a few hectares for the smallest subcatchments to millions of square kilometers for continental scale river basins.

With regards to subsurface contaminants from agricultural practices, saltwater is most appropriately addressed from an aquifer perspective since it most commonly arises from excessive pumping of groundwater, nutrients from a watershed focus because of their close interactions with plants and the vadose zone and their important impacts on local streams and lakes, and pesticides on a case-by-case basis given the complexity of these substances (they can variously be adsorbed onto soil grains, biodegraded in the shallow subsurface, or percolate into deep confined aquifers).

Beyond the hydrogeologically oriented hillslope, catchment, and watershed units, it is worth mentioning that alternative basic study units have been proposed and used, especially when there is a need to characterise hydrologic response with respect to some aggregate of topographic, soil, land cover, land use, geologic, and climatic features, giving rise to what one may term "ecologically similar units" or "hydrologic response units" (Moore et al., 1993; Kite, 1995). Such classifications are especially amenable to GIS processing. 


\section{Scale, variability, nonlinearity, and other issues}

The parameters and processes that characterise natural systems such as watersheds, soils, and aquifers exhibit tremendous variability in space and time. Rainfall, streamflow, vegetation cover, topography, soil texture, hydraulic conductivity, and water table levels, to name a few, reflect and respond to climate, land use, and tectonics, and the interactions between these dominant forces. There is variability both within a given system (e.g., the saturated hydraulic conductivity of a single hillslope can change by orders of magnitude from one point to another), and between systems (e.g., the magnitudes and characteristic time scales of outflow are very different between clayey, sandy, and silty hillslopes).

Some hydrologic processes exhibit characteristic length and time scales of centimeters/minutes, while others act over hundreds of kilometers or thousands of years. Still other processes have no specific correlation or length scale. For instance, the heterogeneity of the porosity of a laboratory soil column may be characterised by its grain size distribution; in small field plots plant root and earthworm channels may be significant in deriving a measure of porosity; for regional aquifers geologic fractures and faults become important in defining this quantity.

Nonlinearity is a feature that is encountered in numerous functional dependencies that govern the behavior and response of water and solutes in porous media. In an unsaturated soil, for example, the moisture content and hydraulic conductivity depend in a highly nonlinear manner on the pressure head. The pressure head in the vadose zone is highest (0) when the soil is saturated and lowest (negative values representing suction) when the soil is very dry and its moisture content reaches residual values. Aside from complicating the mathematics and numerics of modelling subsurface systems, nonlinearity also makes it important to characterise the sensitivity of a given physical process or model output to the components that determine it, as small changes in an underlying parameter or in a model's initial and boundary conditions can result in large changes in an observation or output, and even unstable behavior. This is one of the factors that wreaks uncertainty on model prediction.

Subsurface flow and transport dynamics often exhibit hysteresis or irreversibility, whereby a "forward" process (e.g., soil wetting or solute adsorption) follows a time path or curve that is different from the "backward" or reverse process (e.g., soil drying or solute desorption). Another example of irreversibility is related to saltwater upconing during groundwater exploitation in coastal aquifers. Upconing occurs when the saltwater-freshwater interface below a pumping well rises in response to pumping. Downconing is the reverse process and can occur either actively (water is pumped back into the well to recharge the aquifer) or passively (extraction of water from the aquifer is halted and only natural recharge, determined by rainfall, takes place). Upon repeated cycles of pumping and active recovery, with the same pumping rate used for both extraction and injection of water, the saltwater-freshwater interface may not return to its initial position, as shown in Figure 3. This type of dynamics has practical implications for groundwater exploitation. If pumping is stopped to allow the aquifer to recover and the cone of saltwater to retreat, it is evident that the recovery time must be much longer than the pumping time, even when recovery is enhanced by injecting water back in at the same rate. Normally it will be necessary to begin pumping again from a given well after a certain recovery period (for instance, pumping during summer months when there is little rainfall and agricultural water needs are high, and passive or active recovery during fallow or winter months). Repetition of such a regime over extended periods of time will cause the interface to eventually reach the pumping well, causing costly saltwater contamination of drinking and irrigation water. 


\section{GROUNDWATER POLLUTION FROM AGRICULTURAL SOURCES}

Three main phases can be distinguished in the phenomena of diffuse pollution from agricultural sources:

- generation;

- transport;

- discharge.

The time and space dimensions are fundamental aspects of pollution from agricultural sources. Therefore, each phenomenon, in order to be understood and fully described, must be investigated during all three phases, which are generally manifested in sequence and with a well-staggered spatial distribution.

\section{Generation of loads}

The phase of generation of the diffuse loads is when a polluting event takes place as a consequence of an agronomic practice applied on a cultivated field, for example the spraying of herbicides or spreading livestock manure. The spatial scale is in this case that of the field, i.e. a portion of land cultivated in the same way and homogeneous from the environmental viewpoint, characterised in particular by the same soil and climate. The time scale of the phenomena is widely variable: some occur as practically instantaneous impulses, such as the atmospheric drift of pesticides at time of application, others instead have much longer dynamics that may even last for years, such as nutrient releases in water following phenomena of mineralisation and leaching in soils.

\section{Transport}

The transport phase of the diffuse loads is when the pollutant of agricultural origin moves across the environment; for example when a certain amount of pesticide lost from a cultivated field percolates below the root layer through the unsaturated layer, before it reaches the groundwater. It is interesting to note that, during the transport phase, the polluted environmental resources (air, water or soil) may be at the same time both vectors and receptors of the pollution; therefore, depending on the environmental compartment and territorial ambits to be considered, different successions of transport and discharge phases can sometimes be identified.

The spatial scale for the analysis of transport phenomena is generally much larger than the field, typically the area involved is the catchment (or watershed). The time scale of phenomena is also in this case variable: some pollution events have dynamics on the order of hours (e.g., runoff of water containing agrochemicals after rainfall), but, especially when the problems are addressed in terms of whole ecosystems and on the scale of large territories, the phenomena show multi-annual dynamics (e.g., contamination of aquifers).

\section{Discharge}

The discharge phase is when the pollutant of agricultural sources reaches the resource that can be considered as the final receptor; for example when the amount of pesticide lost from a cultivated field reaches an aquifer, the sea or the mouth of a river or lake. The spatial scale is generally very large as it is usually necessary to understand the effects of the polluting events in the entire water body (a whole lake for example). The time scale for fully describing the phenomena is normally on the order of months or years. 


\section{SALT CONTAMINATION OF AQUIFERS}

Generally speaking, contamination by salt deteriorates water quality for human consumption, while agriculture and irrigation are extremely sensitive to the accumulation of salt in the soil zone. Saltwater is often in delicate equilibrium with freshwater aquifers. When the equilibrium is disturbed, the transition to a new balance could, depending on the scale of the phenomena, require decades (e.g., in the case of disposal of minor salt-containing wastes), centuries (regional scale saltwater intrusion), or millennia (salt dissolution in deep formations) (Frind, 1982). A proper evaluation of the environmental impacts and economic effects associated with salt contamination phenomena therefore requires monitoring and analysis of the short, medium, and long-term response of the threatened system. It is important to adequately characterise the aquifer flow regime and its natural patterns of land recharge and sea discharge, for instance. For heavily-utilised aquifers in semi-arid regions, the flow regime will be particularly sensitive to replenishment by irrigation, artificial recharge, and the rainfall that effectively infiltrates and is not directly lost to surface runoff and evaporation.

Salt is nonreactive, and thus as a solute it is not as difficult to model as some other substances which undergo complex chemical and biological transformations in soils and aquifers. On the other hand, the presence of salt alters water density in such a way as to induce important effects on the pressure and flow fields, and these effects pose some mathematical and numerical difficulties of their own. Density-dependent phenomena in groundwater flow and transport are those in which differences in density between the components of the system have a strong influence on its evolution (Kolditz et al., 1998). Typically the contaminant will be driven downward by gravitational force through the unsaturated zone. If the density of the contaminant is higher than that of water, the contaminant can cross the saturated zone until it reaches the bottom of the aquifer; if the density is lower, the contaminant will spread over the interface (water table) between the unsaturated and saturated zones. In the case of seawater intrusion, the contaminant is denser than freshwater, it normally enters an aquifer at some depth, and can make its way upward into unconfined aquifers and soil root zones aided by excessive groundwater pumping. For salts introduced overland from fertilisers, wastes, salty irrigation water, or salt ponds, complex fingering patterns can occur as the heavier saltwater percolates downward (Schincariol et al., 1994; Simmons et al., 1999).

\section{Seawater intrusion}

In a typical coastal aquifer, seawater and freshwater are separated by an interface across which a mixing or transition zone develops due to dispersive effects (Figure 4). Many modelling studies replace this mixing zone with a sharp front. If, in addition, one adopts the Dupuit assumption of predominantly horizontal flow, the problem of finding the interface may sometimes be solved in closed form. For the more general sharp interface problem, several two-dimensional numerical solutions have been published (e.g., Taigbenu et al., 1984).

The Ghyben-Herzberg relation can be used to determine the shape and position of the sharp interface under static equilibrium conditions (Sherif and Singh, 1996). For example, using 1.025 $\mathrm{g} / \mathrm{cm} 3$ as an average density of seawater, we find that the slope of the sharp interface is 40 times greater than that of the water table. If the water table drops $10 \mathrm{~cm}$, the interface will rise a dramatic $4 \mathrm{~m}$. The Ghyben-Herzberg relation is also helpful in understanding the phenomena of saltwater upconing, which can occur, as seen earlier, in response to a pressure reduction from drawdown around a pumping well. If the pumping rate exceeds a critical level, the saltwater cone will reach the well. One of the weaknesses of the Ghyben-Herzberg relation is that the saltwater interface intercepts the water table at the shore line, meaning that it does not allow for freshwater discharge to the sea. 
When vertical flow and/or dispersion become important, or when the depth of the aquifer at the sea boundary is relatively large, the sharp front approach may not be adequate to describe seawater intrusion (Henry, 1964). As a result, several recent two and three-dimensional models of seawater intrusion handle both vertical flow and dispersion (Frind, 1982; Huyakorn et al., 1987; Voss and Souza, 1987; Galeati et al., 1992).

\section{Soil and groundwater salinisation}

Salinisation of soils and groundwater has been observed in many cases where native vegetation is replaced with cultivated crops (Miller et al., 1981). Practices such as fertilisation and tillage can increase the salt content of soils and drainage water, but the most important cause is irrigation. Irrigation is an agricultural practice of major economic importance, especially in relatively warm and dry climates such as those which characterise the Mediterranean basin. Three processes can cause groundwater salinisation in irrigated agriculture (Suarez, 1989):

- increasing concentrations of salt in the soil due to uptake of water by plants;

- downward movement of salt in the unsaturated layer with leaching water;

- intrusion of saline water as a consequence of pumping groundwater for irrigation.

Crops uptake water and nutrients from the root zone, but salts responsible for salinisation $(\mathrm{NaCl}$ and others) are usually left in the soil because they are not needed for plant growth. Since irrigation water very often contains some concentration of salt, this salt will tend to accumulate in the soil. When irrigation water is applied to cultivated fields the process is seldom $100 \%$ efficient, in that a certain amount of water not consumed by evapotranspiration will percolate to the groundwater. As it flows though the layers of the cultivated soil, the water will increase its salinity due to dissolution of salts previously deposited along the soil profile.

Another possible impact of irrigation is the salinisation of riverine and estuarine environments due to the diversion of water in irrigation canals (upstream saltwater migration). This diversion can reduce the discharge flow below a threshold (minimum vital flux) thereby promoting intrusion of seawater in coastal areas (Zalidis, 1998).

The process of salt accumulation in soils and groundwater can be considered as an example of agricultural diffuse pollution and can be modelled and managed using approaches similar to those used for other nonpoint source pollutants. In modelling the process, consideration of the unsaturated zone is important for analyzing salinisation processes in detail and for investigating specific phenomena such as the water table response and salt accumulation at different rates of irrigation over long time periods.

\section{AGRICULTURE AND GROUNDWATER IN SOUTHERN EUROPEAN COUNTRIES AND THE MEDITERRANEAN}

The Mediterranean is an area of transition between temperate environments and arid ones, where the relationships between human activities and natural resources can assume a wide range of dramatic changes. Typically, in temperate areas, water needs for various uses (agricultural, industrial, etc.) can be satisfied without excessive conflicts and thus environmental issues can play a relevant role in the debate about the use and conservation of water resources. On the contrary, in arid areas the debate tends to be more focussed on economic aspects and the environmental ones are usually neglected. Collin (1995) discusses these topics by defining the differentiation between the continuous water cycle found in the temperate environment and the discontinuous cycle of the arid areas. Very briefly, in the former case rainfall can feed both surface and subsurface water compartments (with runoff and infiltration phenomena respectively) and subsequently groundwater 
can feed the streams originated by runoff, along their course. In this case correct exploitation of groundwater resources is usually posed in terms of avoiding their quantitative and qualitative depletion: keeping the various compartments in equilibrium and maintaining the continuity of the cycle.

In arid areas the water cycle is typically discontinuous; rainfall events are in fact episodic, not allowing significant infiltration to groundwater and determining only some runoff which could eventually be used to fill reservoirs. Groundwater resources which may exist are then disconnected from the other components of the water cycle. In this case groundwater may represent the only available water resource and its use can be viewed as the mining of a non renewable resource; the main issue is then its sustainable management and economic optimisation of multiple uses.

Several common characteristics can be identified to describe the distinctive features of the Mediterranean basin. From a climatic viewpoint, rainy autumns and winters are followed by dryer springs and very dry summers; moreover rainfall distribution and patterns tend to favour high intensity events. These features tend to determine strong water deficits for the major cultivated crops, especially those with spring-summer cycles, but also make possible non negligible runoff and leaching events during the wetter season.

The geomorphology of the Mediterranean is characterised by its relatively recent geologic age, which, besides relevant seismic and volcanic activities, determines the presence of few large plains, with a close contact with mountains and the sea and thus relatively short rivers and small basins, with the exceptions of the Nile, and also the Ebro, Rhone and Po rivers (Grenon and Batisse, 1989).

Three main types of aquifers have been identified by Attia (1998), carbonate karst, alluvial and multi-layered sedimentary. The first is the most prevalent, with very complex hydrogeology and with the largest systems being located on the northern side of the Mediterranean basin. The main alluvial aquifer systems are the Egypt Valley and the Po Valley in Italy. The last type of aquifer is typically found on the southern side of the basin. Alluvial aquifers are in general characterised by high hydraulic conductivity and are in direct connection with the rivers that have a recharge function, and thus are more vulnerable to deep leaching than sedimentary aquifers, which are often protected by confining layers. Karst aquifers are more difficult to generalise due to their complexity and direct dependence on the specific fissure structures and layering.

From the above, the problem of managing agricultural systems with the aim of preserving groundwater resources in southern European countries and the Mediterranean can thus be treated in the more general context of identifying ways for sustainable agricultural development and for fighting against the risk of desertification; overpumping, diffuse pollution and saltwater intrusion are some of the problems that should be dealt with. The Mediterranean, as a relatively dry area, is not among those (i.e., northern Europe) for which the generation of agricultural loads reaches the highest intensity, but still the problem is not negligible. In fact, the seasonal dynamics of climate and agricultural activities, combined with the vulnerability of the environment and with the scarcity of water resources, make the problem of agricultural diffuse pollution of greater relevance. Moreover irrigated agriculture (implying intensive use of agro-chemicals) is still increasing in several areas, and thus also the relevance of the primary sector in the management of groundwater resources.

In summary, in the Mediterranean basin groundwater resources are mainly impacted by agricultural activities as a consequence of:

- extraction of irrigation water all around the basin, but with particular concern in the southern part (mining of non-renewable aquifers);

- use or re-use of water of poor quality for irrigation, especially in those areas with lower rainfall inputs (salinisation of soils and aquifers); 
- use of water for irrigation with application systems of low efficiency especially in those areas with relatively good water supply from rivers or groundwater (pollution, but also salinisation of aquifers);

- use of water for livestock rearing (salinisation and nitrate pollution of aquifers);

- adoption of intensive cultivation systems (horticulture, intercropping, etc.) made possible by the favourable climate, where irrigation water is available (pesticide and nitrate pollution of aquifers).

From the viewpoint of the responses of the environment to the above mentioned impacts, the worst effects can be seen in the case of:

- consistent leaching phenomena induced by excess rainfall or irrigation;

- soils with high leaching potential (high content in sand, low cation exchange capacity);

- geologic conditions characterised by permeable (or fissured) layers;

- aquifers at shallow depth, with short and fast underground paths of water;

- presence of saline groundwater in proximity to freshwater aquifers.

Of course, opposite conditions will favour the preservation of groundwater resources, but it has to be remembered that the complexity of the phenomena and of the interactions between the variables involved make it very difficult to generalise and judge among real world intermediate situations.

Given the described framework of pressures, impacts and responses, various approaches are available to set up planning control programs to cope with the above problems, but in general the following phases should be taken into account (Atkinson, 1987):

1. problem definition;

2. inventory and impact analysis;

3. formulation of alternative control plans;

4. comparative evaluation of control plans;

5. selection and implementation of controls.

The first phase has been discussed above, and in what follows inventory and analysis of the agricultural systems and of the mechanisms generating environmental impacts (phase 2) will be discussed, while in a later section the management of the existing farming systems and ways to put into practice strategies that could minimise environmental impacts (phases 3-5) are described.

\section{ENVIRONMENTAL IMPACT ANALYSIS OF AGRICULTURAL SYSTEMS}

The inventory and analysis of agricultural impacts on groundwater encompasses four strictly linked steps:

- identifying impact indicators;

- monitoring of the phenomena in the real world;

- modelling and simulating the observed phenomena with descriptive models;

- geographical analysis and simulation. 


\section{Identification of impact indicators}

As previously stated, pollution phenomena are complex and consist of alterations of the state of many environmental variables. It is therefore necessary to choose from a long list of possible parameters and variables those which are most representative in various situations and to define their use as environmental indicators (OECD, 1994). An example of suitable indicators for the problems in question are concentrations of nitrate, chloride or pesticides in deep leaching from cultivated fields.

The chosen environmental indicators can be measured within monitoring activities or estimated by simulation models and used as quantitative information for the assessment of alternative hypotheses of agro-ecosystem management. Other indicators should be identified to quantify other aspects which should be considered for the management systems to be evaluated with a multidisciplinary approach: technical indicators (e.g., labour/machinery requirements) and economic indicators (e.g., cost of production factors).

\section{Monitoring of the phenomena in the real world}

When dealing with agricultural production processes, the monitoring phase consists in the acquisition of experimental data by means of agro-environmental trials in the field. Data are gathered that quantify the variations of pollution phenomena due to changes in cropping techniques. A typical monitoring activity consists of collecting samples of leaching water from neighbouring fields in which alternative cultivation techniques are compared (e.g., different ways of fertilising a given crop) (see for instance Giardini and Giupponi, 1995). These activities can make available quantitative information about the magnitude of impacts and the possibility of proposing low impact alternatives. Parallel economic evaluations can propose cropping alternatives with low environmental impact, which are also acceptable in terms of farmers' incomes.

Monitoring activities should be oriented also to the assessment of quali-quantitative characteristics of the water resources to be used (e.g., networks of sampling wells). In this regard it is important to point out that it is not feasible to monitor all aquifers and test all possible pollutants (many hundreds of agro-chemicals are used). Therefore, efficient sampling strategies must be set up to identify critical site/pollutant combinations (Holden, 1986). Moreover, it should be remembered that the orders of magnitude of the parameters in play are extremely variable. For example nitrates in leaching waters can have concentrations between a few and hundreds of parts per million, while total leachate of nitrogen can range between a few kilograms per year (dry climates, reduced fertilisations) to values 10 or more times higher (humid climates, permeable soils, heavy use of livestock manure). The pesticide concentrations in the different environmental compartments are instead on the order of parts per billion and total annual losses are generally measured in grams per hectare.

Monitoring groundwater with the purpose of assessing the sustainability of current land and water management is a complicated issue also because of the difficulties in describing and interpreting the long term dynamics of the system; the complexity can be even increased in the case of monitoring salinisation because of the natural presence of salts in soils, geologic layers and various water compartments.

The complexity of phenomena and of the interactions between natural (e.g., rainfall patterns) and anthropic (e.g., fertiliser management) variables makes purely experimental approaches unsuitable. A modelling approach is therefore usually necessary (Van Keulen and Wolf, 1986) to be able to represent the functioning of the agro-ecosystems and to simulate their behaviour in different hypothetical situations. 


\section{Modelling and simulation}

A sizeable branch of environmental modelling has been developed in the agricultural sector, integrating previous modelling approaches and experiences, mainly in the sectors of hydrology, chemistry and plant physiology. Many models have been proposed in the international literature to simulate the environmental impacts of agro-ecosystems, at various scales and for various purposes (Addiscott and Wagenet, 1985). Those models usually focus in particular on the inefficiencies of agricultural plant production processes (Giupponi, 1995), since the pollution phenomena derive in general from releases of substances not utilised in the production process.

The availability of models calibrated for different environmental conditions is the starting point for simulating scenarios of alternative cropping systems which lead to proposals for sustainable land use (Giardini and Giupponi, 1994). Those scenarios may consist simply of various hypothetical cultivation systems, or more complex combination of technical, economic and social alternatives, to be evaluated for their environmental implications.

\section{Geographical analysis and simulation}

Simulation models can be used to extrapolate experimental or field data, acquired from short-term monitoring campaigns, to much longer time periods (decades or even centuries) under varying environmental conditions (Ritchie, 1987). Analogously, once a model has been calibrated to some reference scenario or event, then with adequate territorial data the model can generate spatial distributions (for instance at a watershed scale) of any number of variables of interest. Territorial analysis, using tools for digital image processing of satellite data (Richards, 1986) and for manipulating geographic information (Burrough, 1986), allows the creation of a systematic framework of information that provides a spatially and temporally distributed description of processes and phenomena, taking into account both natural and anthropic characteristics and the variability inherent in the area being studied.

It is of utmost importance in environmental studies to make use of both simulation models and territorial analysis; indeed many methodologies exist for integrating the two. Simulations can tackle one or several phases of pollution (from generation to discharge to migration) but in general it is the coupling of models and geographic analysis tools that produce a three-dimensional description of how the pollutant is transported, accumulated, and transformed and of how the territorial system responds to various changes that may be introduced. Comparisons can thus be made between, for example, scenarios of land use and groundwater exploitation regimes, in order to identify alternative territorial management policies. The complexity of the phenomena to be modelled and the intrinsic variability of the land and of land uses makes it extremely difficult to obtain accurate or absolute estimates of the magnitude of pollution under different combinations of soil, climate, crop management, and socio-economic conditions. Nonetheless these methods can contribute, at least in their evolution to date, to comparative assessments of alternative scenarios, and can provide substantial contributions to decision support. When models are used for supporting planning activities and management decisions great care should be given to the assessment and documentation of the various sources of uncertainty involved in all the various phase of elaboration: data acquisition, algorithm development, modelling, etc. (Simonovic, 1997).

\section{MODELLING GROUNDWATER AND AGRO-ECOSYSTEMS}

\section{Modelling approaches}

In the representation and simulation of subsurface flow and contaminant transport phenomena and the agricultural processes that affect these phenomena, there are probably as many types of models, 
modelling philosophies, and ways of classifying models as there are sources and types of groundwater contamination (e.g., Renard et al., 1982; Mangold and Tsang, 1991). For instance in the area of diffuse or nonpoint source pollution in agro-ecosystems, various models have been proposed that deal with different aspects of the plant-soil-climate continuum, some focused more on hydrological aspects, while others consider in more detail plant physiology or the chemistry of soilwater-plant interactions. For our purposes we will consider three broad and not necessarily distinct classes of model or modelling approach:

- empirical and regression models, which express some heuristic or statistical connection between observed phenomena, or between "inputs" and "outputs", without concern for the underlying physics, biology, and chemistry, or "inner workings" of the system;

- conceptual and analytical approaches, which greatly simplify the underlying physics/etc for reasons such as tractability, simplicity, and convenience;

- physically-based or process-based models (also sometimes referred to as distributed models), which strive for as complete a description as possible of the underlying physics/etc, within a deterministic or stochastic framework and within the limits of the processes and observations of interest.

This hierarchy also encompasses to some degree the possible ways in which models can be used: the simplest models of the first category can serve as useful screening tools to identify possible cause-effect links in a pollution incident; conceptual models can generate what-if scenarios for impact assessment of, for instance, alternative cultivation practices or pesticide application rates; the third class is ideally suited to research and can be used to conduct exploratory simulations to test new hypotheses and parameterisations, for example. In practice there is a great deal of blurring and overlap between the ways different models can be used, as will be shown later in an example of a regression/empirical approach and in the presentation in some detail of a standard process-based model for groundwater flow and transport.

We can include, as a fourth category to the three above, that of combined approaches, in the sense of composite models which use one approach for a given subset of processes or subsystem, and another approach for a second subsystem. Process models, based as they are on fundamental governing equations, are the most multi-purpose, flexible, and extendable of the approaches, though these comprehensive models are not without their limitations and drawbacks. Chief among these are over-parameterisation and uncertainty, in the sense that most models have not been validated in all their detail, owing in part to a mismatch between model complexity and the level of data which is available to test and calibrate the models. In applying such models for large scale studies, computational requirements can also be prohibitive.

\section{Implications of scale and variability to modelling}

The issue of variability and its links to problems of scale has been one of the dominant themes in hydrology for the past 15 years (Bloschl et al., 1997). It is an issue that has bearing on the enormous difficulties in both monitoring and modelling hydrologic systems, as already alluded to, and on efforts to quantify and minimise the uncertainty inherent in parameterising, calibrating, and using, in an operational and decision-support sense, process-based models.

On a practical level, considerations of scale and variability play a decisive role in the design of any field-based water resources study. Addressing the interplay between groundwater pollution and European agricultural policy, for instance, would appear to require a large scale study site that embodies a wide range of processes and generates inflows and outflows of social and economic significance (affecting a large population, or representing a sizable fraction of total agricultural production, for instance). But a large scale study requires enormous amounts of data, and may not be amenable to a process-based modelling approach. Studies restricted to smaller regions can 
nevertheless be useful in evaluating the relative importance of pollutant transport and transformation mechanisms and in assessing the effectiveness of various remediation strategies. The results of such studies can then be implemented at larger scales, with consequent implications for national or European agricultural practices. We mention a few examples that illustrate this:

- The important buffering effect of riparian forests or wetlands on nitrate discharges can be readily studied using a process-based model applied to a hillslope or small watershed.

- The models of an agro-ecosystem deal with the plant-soil-climate system at various scales (both spatial and temporal), but in general the limits of the system (at which estimates of pollution loads are made) are defined as the "bottom of the root zone", for leaching, and as the "edge of the field", for surface runoff (see Figure 1).

- The salinisation cycle, which involves seawater intrusion or saltwater upconing in deep confined aquifers, extraction of this saltwater by pumping, use of the pumped water for irrigation, and consequent accumulation of salt in soils as crops uptake mostly freshwater, can be modelled in a two-stage process using first a 3-dimensional aquifer model and then a onedimensional vertical flow and transport model with a simple treatment of water and solute (salt) uptake by plants.

- Physically-based numerical models can be used to individually simulate nonpoint source pollution over many small basins or fields that are representative of a larger region of interest (country or continent, for instance). The simulation data can then be statistically analysed to obtain the spatial and temporal patterns of solute concentrations, and the results aggregated to enable quantification of the large scale pollution characteristics.

\section{Empirical and regression models: An example for regional water quality assessment}

We describe an example from the recent literature that deals with large scale watershed pollution, predominantly nonpoint source nutrients. The example will be used to describe some of the fundamental hydrologic processes involved, the data requirements, and the important inputs and outputs, as well as to elucidate this interesting regression modelling approach. Smith et al. (1997) developed a regression methodology to derive total phosphorus (TP) and total nitrogen (TN) concentration and transport rates for the entire conterminous United States. The model makes use of a digitised network of stream reaches and associated land surface polygons, and data from 414 water quality stations, located near the outlets of selected watersheds, that are part of the U.S. Geological Survey's National Stream Quality Accounting Network (NASQAN). The statistical regression model "relates measured transport rates in streams to spatially referenced descriptors of pollution sources and land surface and stream channel characteristics"I.

For the total nitrogen analysis the authors considered: $5 \beta$ factors (sources) - point sources, fertiliser application, livestock waste production, atmospheric deposition, and nonagricultural land; $8 \alpha$ factors (land surface characteristics) - temperature, slope, soil permeability, stream density, wetland, irrigated land, precipitation, and irrigated water use; and $3 \delta$ factors (stream channel characteristics) - slow (stream flow $Q<1000 \mathrm{ft}^{3} / \mathrm{s}$ or $28.3 \mathrm{~m}^{3} / \mathrm{s}$ ), medium, and fast $(Q>10000$ $\mathrm{ft}^{3} / \mathrm{s}$ ) flow classes.

The results obtained upon fitting the model by nonlinear least squares estimation suggest that for total nitrogen the most significant land surface parameters are temperature, soil permeability, and stream density, and that the channel decay coefficients decrease as the stream size (or flow rate) increases. High temperatures increase the rate of denitrification, and therefore can be expected to decrease the delivery of TN to streams. Highly permeable soils are expected to allow more contaminants to enter the subsurface, where the contaminants are then subjected to additional degradation processes and longer travel times to the stream channels. Stream density (or drainage 
density) is the ratio of channel length to watershed drainage area, and thus higher stream densities imply shorter overland travel distances for contaminants before reaching the stream.

The model developed by Smith et al. (1997) is empirical, but nonetheless has a number of very appealing features:

- its simple structure and statistical nature allow investigation of a wide range of factors that affect (or may affect) TN and TP transport rates;

- it is "parameterised" according to quantities that can be easily measured (although this also has drawbacks in that these parameters can lump together a number of physical effects, thereby making it difficult to identify or isolate important underlying processes);

- an enormous amount of data can be analysed (in fact a large amount of data is normally a requirement for obtaining statistically significant results);

- the model is not physically-based, but because it relates water quality to spatially referenced watershed attributes, it has some interpretive capabilities that provide a "link between the descriptive and explanatory aspects of assessment". This can be used directly in water resource decision-making frameworks, or it can yield insights to guide the construction of more complex process-based models.

The authors conclude that the developed methodology and model is "an important adjunct to data collection in regional water quality assessment programs as a means of addressing the problems imposed by limited sampling resources, network bias [that arises from the fact that specific or known pollution sources and regions are often monitored more thoroughly than others], and basin heterogeneity".

\section{Process-based models}

The standard mathematical model governing water flow and chemical transport processes in porous media is based on the partial differential equations of fluid mass and momentum balance and of solute mass balance. These equations are described here in their most general three-dimensional form; depending on the application, simplification to one or two dimensions is common practice. These equations can be extended and elaborated in a variety of ways to enable treatment of numerous specialised or more complex cases (Addiscott and Wagenet, 1985; Parker, 1989; Segol, 1993; Gallo et al., 1996; van Genuchten and Simunek, 1996; Bixio et al., 1999). In the following section the extension of the basic model to the problem of saltwater intrusion will be given; other extensions include formulations for treating nonequilibrium chemical transport, biodegradation, multi-species and multiphase phenomena, radionuclide decay chains, preferential flow (fractures, macropores, cracks), water uptake from plant roots, coupled heat transfer and moisture flow, and coupled subsurface and overland flow (surface runoff and channel routing).

Flow in variably saturated porous media is governed by Richards' equation ${ }^{\text {II }}$. This equation is strongly nonlinear due to pressure head dependencies in the relative hydraulic conductivity and general storage terms and must be solved iteratively using linearisation techniques such as NewtonRaphson (Paniconi and Putti, 1994). These dependencies have been extensively studied and are expressed through semi-empirical constitutive or characteristic relations describing the soil hydraulic properties (e.g., van Genuchten and Nielsen, 1985). The transport equation ${ }^{\mathrm{III}}$ describes diffusion, dispersion, and advection processes as well as simple chemical reactions (linear equilibrium adsorption and radioactive or biodegradation decay). For the numerical discretization of the flow and transport equations, a standard finite element Galerkin scheme is used, with tetrahedral elements and linear basis functions, complemented by weighted finite differences for the discretisation of the time derivatives. For an introduction to finite element techniques in engineering and groundwater applications, see Zienkiewicz (1986) and Huyakorn and Pinder (1983). The finite 
element discretisation yields large sparse systems of equations which are solved using efficient preconditioned conjugate gradient-like methods (Gambolati et al., 1996).

To complete the mathematical formulation of the flow and transport problem, initial and boundary conditions need to be specified. Initial conditions consist of the state of the system at the start of the time period being simulated. When the model is discretised, this information is given in terms of pressure head and concentration values at each node in the interior of the domain, where the domain corresponds to the system (aquifer, watershed, etc) being modelled. Boundary conditions are instead required for the entire simulation period, but only at the nodes which constitute the boundary of the simulation domain. This information can take the form of assigned pressure head and concentration values (Dirichlet type), prescribed flux values (Neumann type), or a mixture of these (Cauchy type). Different segments of the boundary can have different types of boundary conditions.

In addition to the various parameter values that need to be assigned a priori in the model (saturated hydraulic conductivity, porosity, dispersivities, coefficients in the storage and relative conductivity expressions, etc), the initial and boundary conditions constitute another set of model inputs. Detailed or accurate values for these inputs are not always readily available or easily measured, and approximations, such as assuming the porous medium to be homogeneous, are often necessary. In the case of initial conditions for the transport model, selecting the start of the simulation period to be prior to the occurrence of contamination means that zero concentration can be initially assigned to all nodes. For boundary conditions, knowledge of the geologic and hydrographic features of the simulation domain is important, as is careful delineation of this domain. Rivers, watershed divides, a layer of bedrock underlying an aquifer, and other such natural boundaries can all be treated relatively easily.

\section{Coupled flow and transport model of saltwater intrusion}

The mathematical formulation for the three-dimensional finite element model that treats densitydependent variably saturated flow and miscible (dispersive) salt transport is developed as an extension of the basic equations described in the previous section. The formulation and procedures form the basis of the CODESA-3D (COupled variable DEnsity and SAturation) model (Gambolati et al., 1999).

The mathematical model of density-dependent flow and transport is expressed in terms of an equivalent freshwater head $h$, defined as (Huyakorn et al., 1987; Frind, 1982; Gambolati et al., 1993) $h=\psi+z$ where $\psi=p /\left(\rho_{o} g\right)$ is now the "equivalent freshwater" pressure head, $p$ is the pressure, $\rho_{o}$ is the freshwater density, and $g$ is the gravitational constant. The density $\rho$ of the saltwater solution is written in terms of the reference density $\rho_{o}$ and the normalised salt concentration $c: \rho=\rho_{o}(1+\varepsilon c)$ where $\varepsilon=\left(\rho_{s}-\rho_{o}\right) / \rho_{o}$ is the density ratio, typically $<<1$, and $\rho_{s}$ is the solution density at the maximum normalised concentration $c=1$. Depending on the application, $\rho_{s}$ can represent, for instance, the density of seawater or of the solution of a salt pond where the concentration is highest. The dynamic viscosity $\mu$ of the saltwater mixture is similarly expressed as a function of $c$ and a reference viscosity. With these definitions and constitutive relationships we can derive the model describing saltwater intrusion phenomena ${ }^{\mathrm{IV}}$.

Coupling in this model is due to the concentration terms that now appear in the flow equation and the head terms that appear in the transport equation via the Darcy velocities. In the simpler case of non-density-dependent flow and transport, the system is coupled only through the head terms in the transport equation. In this case there is physical coupling, but mathematically the system can be reduced ("decoupled") and solved sequentially, first the flow and then the transport equation, without iteration. For the density-dependent case, the system is irreducible and any sequential solution procedure requires iteration. The importance of coupling, and the degree of nonlinearity 
now present in the transport equation (in contrast to the basic model where only the flow equation was nonlinear, for the case of unsaturated porous media), are expected to decrease as the density ratio $\varepsilon$ decreases or as dispersion becomes dominant (Putti and Paniconi, 1995).

\section{Parameter estimation and model calibration}

Obtaining sufficient and reliable input data to assign to the various parameters and initial and boundary conditions of simulation models can be an onerous task. Given that inevitably in models of natural systems such as aquifers and watersheds the available data tend to be scarce or inaccurate, there has been much research devoted to methodologies for parameter estimation and model calibration. The procedures commonly used range from ad hoc trial-and-error methods to sophisticated mathematical/statistical inverse algorithms. In a recent and exhaustive study comparing seven inverse approaches to estimate parameters for flow and solute transport models (Zimmerman et al., 1998), the authors concluded that "...the most important factor for achieving a successful solution was the time and experience devoted by the user of the method". This underlines an important point that applies not only to inverse methods, but more importantly to groundwater models themselves: Comprehensive physically-based numerical models are powerful tools, and are increasingly being equipped with user-friendly graphical interfaces and instant post-processing utilities (plots, maps, summary reports, etc), but their proper use for analysis and decision support will continue to require on the part of the user some knowledge of the underlying processes and their interactions, of the mathematical representation of these processes via equations and parameters, and of the particular features of the computer implementation - these are elements that can make the difference between a successful simulation and a meaningless one.

\section{THE ROLE OF GEOGRAPHIC INFORMATION SYSTEMS}

\section{Model inputs, outputs, and derived information}

The instruments that are used for monitoring and measuring physical, chemical, and biological processes in a natural system such as an aquifer or watershed provide input data to simulation models. The models recast this input data in the form of boundary conditions and other external forcing terms (such as pumping wells), initial conditions, and values for various physical and numerical parameters. The models then produce outputs such as multi-dimensional fields of basic and derived variables at selected times (pressure heads, pollutant concentrations, water table levels, moisture contents, etc), hydrograph output showing the flow rates at a designated point (a catchment outlet or a monitoring station), and diagnostic output summarising the performance of the model run. This input and output information reflects the status and evolution of atmospheric, soil, and subsurface resources, and is normally utilised by scientists in "raw" form. Roughly speaking, a single number gives the value of a specific parameter or state variable at a given point in time and space. This is not normally the form or nature of information required by a decision maker, resource manager, or policy analyst, for a number of reasons:

- the parameter or variable may not be meaningful or directly utilisable by the policy analyst raw data needs to be converted to another form;

- the data may not be at a space or time scale consistent with the needs of analysis - raw data needs to be (dis-)aggregated;

- the analyst requires information that is represented or contained in a number of parameters/variables - policy information needs to be derived from raw data; 
- the information required is not just process-based or scientific data, and must be combined with other data (demographic, economic, medical, etc) - raw data needs to be integrated with other data sources and types.

So an important issue that arises is that of transforming model inputs and outputs into format and content useful for non-scientist end-users, in the form of maps, indicators, indices, forecasts, scenarios, statistics, and so on. Given that much of the raw data is spatio-temporal in nature (think of water quality measurements from a monitoring network, a satellite image of land cover, or a calculated map of salinity isolines), it is natural to use a GIS as a primary tool for data organisation and transformation, and indeed the role of GIS in hydrology and water resource studies is wellrecognised (Leipnik et al., 1993; Maidment, 1993; Moore et al., 1993).

\section{What is GIS?}

The trend of growing awareness and concern towards the environment and the need to make rational choices to deal with environmental issues have gradually brought geographic information generally intended as "information which can be related to a location on the Earth, particularly information on natural phenomena, cultural, and human resources" (AGI, 1991) - to be considered as the basis for an improved understanding of many of the problems afflicting our planet. In parallel, the complexity and the heterogeneity of geographic information, as represented by maps, remote sensing imagery, monitoring network logs, socio-economic data, etc has required the development of adequate technologies for its representation, processing, and management (see UNEP, 1999 for an overview). Geographic information systems (GIS) have evolved, since the 1960 s, in response to these needs and in tandem with the evolution of related technologies such as database management systems, visualisation, geostatistics, and remote sensing (e.g., Ehlers et al., 1989). As an evolution of cartography-based applications, geographic information systems have naturally assumed a role of primary relevance in domains such as natural resource management and land planning. At the same time, GI technologies have developed also within other domains, such as facility management, tourism, telecommunications, and transport.

A general definition of a geographic information system, highlighting its key characteristics, can provide a useful starting point in describing the possible role of such a technology in policy support for environmental or hydrologic applications. In the various definitions of GIS given in the literature $^{\mathrm{V}}$, common features that emerge are those of the interaction between institutions, either represented by analysts or policy makers, the importance of data, and the availability of an array of support tools. Only an appropriate balance between these components can insure the further evolution of GIS from a strictly technical solution to a tool accepted in the policy process.

Environmental data is generally complex, voluminous, and characterised by heterogeneities and discrepancies due to often ad hoc data acquisition over time. Analysis tools and methodologies which are consolidated within a single discipline may need to be adapted when brought into a multidisciplinary arena. In the past few years these issues have been clearly identified and recognised as a priority by the major subjects responsible for the acquisition and management of geographic information, such as national mapping agencies, data providers (e.g., the European Space Agency), and communities of software developers and users (e.g., the OpenGIS consortium, OGC Technical Committee, 1998). Concerning data, the adoption of accepted standards for their content and description (or "metadata") should enable providers to produce data sets with known quality and that are harmonised across boundaries, spatial scales, and geographic projection, allowing a seamless merging of the most diverse sources of geographic information.

The availability of metadata represents the basis for the simplification and enhancement of directory and data retrieval systems which are fundamental for the exchange of information between the numerous players involved in the analysis and definition of policies related to environmental problems. The scenario which is envisioned in the evolution of GIS is strongly influenced by the 
development of increasingly powerful information and communication technologies (European Commission, 1998), and is represented by the creation of "spatial data infrastructures", both at a national and trans-national level, which should allow geographic data and knowledge to be located and shared.

\section{GIS and environmental/hydrologic modelling}

Understanding the spatio-temporal behaviour of hydrologic processes and state variables at large scales involves the use of many different types of data, obtained from field measurement, remote sensing, digital terrain models, and numerical simulation. A GIS support is particularly valuable at the modeller's level. For example, the design of a numerical grid representing an aquifer for application of a simulation model can be automated and more directly linked to the mappable features in the study area. This makes the process more intuitive and relieves the user from tedious and error-prone processing tasks (Kuniansky and Lowther, 1993), while improving the accuracy in the description of the site under examination. At the same time, the fact of undertaking a modelling study in a GIS context provides a basis for the simplification of the interaction between the different players involved (data providers, modellers, and decision makers) through the establishment of a common data structure.

With the complexity of models and the variety and volume of data that needs to be processed, preand post-processing tasks related to modelling efforts rely not just on GIS, however, but on a host of other software tools such as scientific visualisation systems, image processing software, and database management systems. Combining these data, models, and tools into a robust and userfriendly system is a research topic that has seen approaches ranging from so-called "loose" integration to "tight" integration (Batty and Xie, 1994; Livingstone and Raper, 1994; Nyerges, 1994; Paniconi et al., 1999). Another approach to GIS-model integration is to move from modelling linked to GIS to modelling within GIS. Generally, this is achieved by implementing fundamental modelling "primitives" as intrinsic GIS functions, such as the advection-dispersion equation for groundwater transport, or by characterising spatial response functions, via time-area diagrams for example (Maidment, 1996). The outcome of such an approach is clearly dependent on the type of model being considered, and several models have already been successfully integrated within different GIS packages.

Three examples of GIS-integrated land surface or subsurface models for hydrologic and agricultural applications are the DRASTIC methodology for groundwater vulnerability mapping (Merchant, 1994) and the AGNPS and ANSWERS models for nonpoint source pollution modelling (Wilson, 1996). A fourth example is BASINS (EPA, 1998), an integrated watershed-based modelling system for water quality assessment and analysis of point and nonpoint sources of pollution. BASINS is a tool aimed specifically at agencies responsible for pollution control and water policy and regulation. In particular, it is intended as a support tool for the establishment of total maximum daily loads (TMDLs) for a wide variety of pollutants, as required of all U.S. states over the next 15 years by the Clean Water Act. One of the distinctive features of BASINS is that it integrates not only software tools (including GIS and simulation models), but also data. Indeed data is a key component of BASINS, with 1-2 gigabytes of geographic and environmental data per EPA Region distributed as part of the software package (there are 10 EPA Regions in all). This approach ensures compatibility and consistency between BASINS implementations on different watersheds, and encourages adherence (for any additional data introduced in a local application) to established data and metadata standards such as that of the FGDC (Federal Geographic Data Committee). The data supplied with the BASINS system is derived from a wide range of U.S. agencies (NASA, USGS, EPA, etc) and includes cartographic, land use, soil, stream, digital elevation, meteorological, water quality, and pollutant loading data. 
While consistent progress has been achieved during the past years in the development of integrated GIS/modelling solutions, it has been observed that if we accept the concept of GIS as a methodology for handling spatial location and interrelationships, while environmental modelling handles system states and dynamics, full integration between the two will always suffer from a number of representational compromises. In this regard substantially different strategies that exploit object-oriented modelling of geographic features have been proposed (Raper and Livingstone, 1996; Crosbie, 1996).

Whichever the technical solution adopted to integrate geographic databases, GIS functionality, and ancillary tools with simulation models, the increased usability of the resulting system must be adequately supported in order to avoid improper or inexpert use (which paradoxically may be an increasing risk as such tools become more sophisticated yet easier to use). This has led to the suggestion of yet another strategy for GIS-model integration, plausible in situations where the use of sophisticated analytical tools is not warranted by the amount or quality of data available, whereby reliance on quantitative estimates is replaced by a qualitative understanding of the pattern of hydrological response and simple GIS-based reasoning is used to assist in the decision-making process (Grayson et al., 1993).

\section{GIS and policy support}

As already described, the data from environmental monitoring networks and the results from simulation models must be presented in a form that is understandable and effective for the policy maker. In this context, GIS can play an important role in, for example, conflating data from local to global level (e.g., provincial and regional), re-aggregating cell-based information to indicators referred to administrative boundaries, deriving complex maps by means of spatial analysis (overlay, buffering, map algebra), generating tabular and chart reports (a natural complement to the mapbased information normally provided by a GIS), and supporting what-if scenario simulations (possibly designed in a way that avoids the dysfunctional separation of the roles of analyst and decision-maker (Nyerges, 1994)).

Geographic information systems, notwithstanding the highly intuitive nature of map-based representation of information, should not however be considered as the sole or dominant tools to be proposed in a decision support system for a policy maker. Rather, GIS should be placed at the same level as other information management tools, together with visualisation (in general) and databases (Peirce, 1998). Identifying the priority issues raised by the need to transmit information from scientists and analysts to policy makers leads in turn to the definition of strictly technical problems, where GIS play an important role. However, since any tool applied in the definition of a policy acquires a political connotation in itself, we should also consider whether the application of GIS to the policy process differs from the application of other more "traditional" tools or models, such as those used for economic planning or welfare policy analysis. In this respect, King and Kraemer (1993) suggest that geographic information has a greater possibility, compared to other modelling bases, to act as a "boundary object" with a greater acceptance by different parties, while at the same time the very breadth of GIS applicability to policy problems makes it likely that GIS will be drawn into many different kinds of policy debates.

An example of the change in perspective from modeller to analyst or policy maker can be of use in demonstrating how and - depending on the specific issue considered - to what extent a GIS support can be of use to transmit information between these players. Let us consider a sample set of questions which the policy maker might pose, in relation to a site that is at risk of saltwater intrusion, in order to make rational judgements regarding possible remediation, conservation, or regulatory actions:

1. Which are the zones or pumping wells exceeding or at future risk of exceeding maximum allowable salinity levels for a variety of water uses (urban, industrial, agricultural)? 
2. Is the freshwater-saltwater interface advancing, receding, or at equilibrium?

3. What are the threshold or optimal irrigation rates to avoid salt buildup in soils and to enhance flushing?

4. Can a localised aquifer recharge strategy be identified that remediates extreme salinisation?

5. Can regional (aggregate) pumping location and rate regulations be designed that balance aquifer use and conservation pressures?

6. What are the likely sources or origins of the salinity in the soils and aquifers?

7. Is the monitoring network adequate? How can it be improved? (distribution of monitoring stations, frequency of data acquisition, what data has to be collected?). At what cost?

Table 1 lists the input and output data needed and generated by a generic process-based seawater intrusion groundwater model. For each of these questions or issues Table 2 indicates the data that is pertinent to the issue (in this table "other" refers to non-process or scientific data, such as socioeconomic data). Given that virtually all the types of data presented in Table 1 are characterised by spatial variability (even though a number of the parameters listed are in practice assumed to be constant, but this has mainly to do with simplifications or deficiencies in the model structure or in the data acquisition), there is a clear need for GIS technology to adequately process the information. Moreover, the input data are seldom obtained from a single source, thus data integration is another critical task that can be adequately addressed by GIS. Finally, the many-to-one mapping between input/output data and a given policy issue that is apparent in Table 2 gives a good idea of the extent to which model data needs to be aggregated and transformed, via GIS and other tools, to address relevant policy issues.

\section{IDENTIFYING SUSTAINABLE AGRICULTURAL SYSTEMS}

Recognising the existence of environmental impacts of agricultural origin (salinisation or pollution) normally implies a public will to intervene to minimise or eliminate the observed negative phenomena. The possible strategies of intervention obviously differ depending on the type of impact and the socio-economic and environmental contexts, but, in general, policies to combat both salinisation and pollution of groundwater resources can be threefold (Umali, 1993):

- issue measures to make efficient use of water;

- $\quad$ sustain the adoption of environmentally sound production methods;

- encourage wider use of environmental impact assessment of water exploitation plans.

This section delves deeper into the understanding of the interface between technical aspects and that of decision making and policy design and development.

Generally it is more efficient to intervene with actions to prevent or reduce to an acceptable level environmental impacts at their sources (i.e., the generation phase). In this case the most widely used approach is that of internalising the costs of control measures $(F A O, 1996)$ by creating the economic interest for the farmers to adopt more efficient production processes and in particular socalled eco-compatible cropping systems (i.e., with low environmental impact). This can be done through agricultural policies that create conditions of economic advantage for these systems, or with appropriate land planning measures or regulations (Giupponi and Rosato, 1995).

In the transport phase it is usually more difficult to intervene, especially when dealing with subsurface fluxes of pollutants (i.e., impacts on groundwater). Nevertheless, pollution control actions on surface waters, which may have indirect effects on groundwater return flux, can be carried out, for instance with interventions on the riparian vegetation (e.g. plantation of buffer 
strips), or with operations to oxygenate the water body, such as waterfalls, or with constructed wetlands for phyto-remediation (Welsh, 1991). When pollutants reach the final receptor (aquifer, lake, lagoon, etc,) fewer options are available, for example based on treatment plants for cleaning the water and restoring an adequate quality for specific needs (Kinzelbach and Schafer, 1993) such as making water suitable for drinking.

In the context of making technical knowledge available for defining policies in the agrienvironmental sector, the information gained on the phenomena generating environmental impacts is a precondition to setting up strategies and interventions to control the diffuse loads, with the aim of minimising their magnitude (see for instance Yurdisef and Jamieson, 1997). A possible methodological approach for such purposes, recently developed and applied to the area of the Venice Lagoon watershed (Giupponi and Rosato, 1998, 1999), comprises the following main phases:

- definition of evaluation indices;

- definition of alternative scenarios;

- calculation of indices;

- multi-disciplinary evaluation and decision-support.

\section{Definition of evaluation indices}

Assuming that an adequate set of indicators has been identified during the phase of inventory and analysis, adequate methods and data for describing the agricultural management systems should be already available. The aims of the intervention having been precisely defined within the broad context of pollution control, it is then necessary to define suitable algorithms to apply to the values of indicators to obtain concise indices on which to base the evaluation of the alternatives (Giupponi, 1998). The alternatives are in general made up of possible scenarios of agricultural land use deriving, for example, from the adoption of different government and planning acts or from the adoption of possible new technologies. An environmental indicator, such as a time series of values of pollutant concentrations, can thus lead to the calculation of various kinds of concise evaluation indices to quantify for instance the risk for aquatic life in surface water or the suitability of aquifers that supply drinking water. According to the aims and priorities of the interventions, the values of indices can be elaborated in various ways to be used in multi-disciplinary evaluation (e.g., costbenefit analysis or multi-criteria analysis) together with the results of the economic and technicalagronomical approaches.

\section{Definition of alternative scenarios}

Variations to socio-economic and policy scenarios usually determine changes in farmers' decisions about production processes and management techniques, which reflect onto changes in land use at the territorial scale, and finally to changes in potential impacts. New policies should therefore be based upon in depth knowledge of agricultural systems and their behaviour in response to external driving forces (i.e., policy and market contexts), to which the agricultural sector has shown itself to be quickly responsive. Many example are available in the history of the Common Agricultural Policy.

In the past, the introduction of incentives per yield unit of some crops pushed farmers to increase both the surface cultivated with subsidised crops and to intensify cropping techniques (e.g., higher fertiliser rates). More recently, incentives per unit of cultivated surface have increased the areas planted with those crops, but not the cropping inputs. These two policies for supporting farmers' incomes are evident examples of socio-economic actions that can cause dramatic and unexpected environmental effects. Changes in the ratios of costs and incomes among alternative crops 
determine the choices of farmers who consequently vary cultivation techniques, crop allocations within the farm, or even completely abandon or take up new crops and cultivars.

Many factors affect farmers' choices (e.g., farm size and typology, labour availability, risk aversion, etc.). Therefore, adequate surveys of farmers' strategies and behaviour in a given area must be carried out to build farmer decision models and then to forecast the possible variations in land use in the different parts of the land. On this basis, alternative land use scenarios could be identified and implemented to build a framework for the use of modelling to feed the evaluation procedure with quantitative data (agri-environmental indices of agricultural systems).

\section{Calculation of the evaluation indices}

Once the parameters that describe the types of land use are known (proportion of hectarage of the different crops, cultivation techniques, etc.), it is possible to calculate the associated impact indices and compare the environmental effects of the proposed alternatives (Giupponi and Ghetti, 1996). Operating within the context of a geographical information system it is also possible to manage huge data sets (many crops in combination with different agronomic techniques, different environments, etc.) in a spatially distributed way. This allows one to obtain very efficiently not only a representation of the estimated magnitude of pollution phenomena, but also spatially explicit systematic and quantitative comparisons between the alternative scenarios: for example, maps of the differences in impact associated with two or more alternative policy scenarios (Giupponi and Rosato, 1999).

\section{Multi-disciplinary evaluation and decision-support}

When adequate information bases exist on the production processes and environmental phenomena on the one hand, and on the territorial features on the other, it is possible to assemble the results of environmental modelling and other approaches and to carry out multi-disciplinary evaluations. As agronomic, economic and environmental approaches generally produce trends in the values of the indices, multicriteria analysis approaches are often adopted to formulate the choices and decisions. In some cases proper decision-support systems (DSS) can be produced, that the authorities or individuals in charge of management at various levels can utilise to support their own choices (UNITAR, 1995), on the basis of quantitative information on the foreseeable effects of those choices. It is possible, for example, to attempt to compare the environmental effects of different cropping systems in the various parts of the territory, to highlight possible conflict situations and to plan interventions to ensure that higher impact cropping systems are not practised in the more vulnerable areas.

To be efficient a DSS must have an extremely simple interface with the user and must present the results of scenario simulations within a very short time. Only in this way can the user (public administrator, extension officer, professional) effectively gain an advantage from the knowledge of the experts in the various disciplines implemented in the system and be eager to compare his own opinions with the indications that come from the DSS. The results of the elaboration must also be as well-documented as possible to be able to refer to the criteria adopted, the decisional mechanism used and the degree of uncertainty.

\section{CONCLUDING REMARKS}

There are many ways to classify groundwater and soil contaminants and the nature of their sources (Domenico and Schwartz, 1990): according to localisation (point source for fixed, small scale sources that produce well-defined plumes - e.g., landfills or a leaking pipeline - and nonpoint source for diffuse, larger scale contamination - e.g., herbicides applied to farmland areas or runoff 
from urban centers); according to origin (industrial, military, agricultural, urban, and natural); according to chemical or biological properties (radioactive substances, trace metals, other inorganic species, nutrients, organic chemicals, and microbial pollutants). We have focused on a small but important set of nonpoint source contaminants that are commonly (though not exclusively) associated with agricultural practices encompassing pesticide and fertiliser use, groundwater pumping, irrigation, and animal farming and grazing. These contaminants are nutrients, pesticides, and saltwater. The fundamental processes that determine the production, fate and impact of a groundwater contaminant have been described, and we have given an overview of the basic mathematical equations governing fluid flow and solute transport in porous media, developing in more detail the numerical model for saltwater intrusion. This process-based modelling approach has been placed in the context of other approaches, with examples illustrating how various models can be used in practice and the precautionary steps needed to avoid misusing them.

Some of the important issues and concepts that accompany efforts to gain a better understanding of hydrologic behaviour and an improved capacity to model and predict this behaviour have been addressed, with particular emphasis given to the problem of transforming model inputs and outputs to information that is useful and useable for policy analysis and resource management. To this end, it should be emphasised that the theoretical knowledge base for understanding and describing agricultural impacts on groundwater is well-developed. Technologies such as simulation models and GIS can, in this regard, provide a bridge to real world situations and problems, and allow the efficient organisation of information management systems and, beyond this, the construction of effective decision support systems. An extensive list of possible technical solutions is available, as we have shown, from which, using these information technologies, rational choices can be made as to those most suitable in any given situation.

It is important, in the implementation and application of modelling, GIS, and DSS frameworks as resource policy and management tools, that the appropriate approach (more than the specific model or software package) be identified, according to the problem at hand (type of pollution, scale of application and impact, data requirements and availability, end-user needs such as prediction or hypothesis testing, etc). This will require, in addition to ongoing progress in the development of technological systems, closer interaction between the disciplines. Specific research areas that can benefit from such interaction include:

- more effortless integration and exchange of data deriving from monitoring and simulation and needed for defining and evaluating strategies and policies;

- further evolution in the development of software tools in terms of user interfaces and the processing and presentation of observation data and simulation results;

- study of methodologies for closer coupling between physical and socio-economic models, beyond current techniques based on introducing simple constraints in an optimisation framework;

- more efforts devoted to multidisciplinary case studies that will serve to test and validate coupling and integration methodologies.

\section{REFERENCES}

Addiscott, T. M. and R. J. Wagenet, Concepts of solute leaching in soils: a review of modelling approaches, J. Soil Sci., 36, 411-424, 1985.

Association for Geographic Information (AGI), GIS Dictionary, A Standards Committee Publication of the Association of Geographic Information, Version 1.1, STA/06/91. UK, 1991. 
Atkinson, S. F., Ground water contamination from saltwater intrusion and limitations on agricultural activities. In: D. M. Fairchild (Ed.) Ground Water Quality and Agricultural Practices. Lewis Publisher, Chelsea (MI), 1987.

Attia, F. A. R. The vulnerabiliy of groundwater to pollution and strategies for its protection under the farming conditions in the Mediterranean Countries. Medit (2/98)53-59, 1998.

Band, L. E., Topographic partition of watersheds with digital elevation models, Water Resour. Res., 22(1), 15-24, 1986.

Batty, M. and Y. Xie, Modelling inside GIS: Part 1. Model structures, exploratory spatial data analysis and aggregation, Int. J. Geographical Information Systems, 8(3), 291-307, 1994.

Bear, J., Hydraulics of Groundwater. McGraw-Hill, New York, NY, 1979.

Bear, J., A. H.-D. Cheng, S. Sorek, D. Ouazar and I. Herrera (eds.), Seawater Intrusion in Coastal Aquifers - Concepts, Methods and Practices. Kluwer Academic, Dordrecht, The Netherlands, 1999.

Bixio, A. C., S. Orlandini, C. Paniconi and M. Putti, Coupled surface runoff and subsurface flow model for catchment simulations. In: J. Feyen and K. Wiyo (eds.) Modelling of Transport Processes in Soils at Various Scales in Time and Space, 583-591, Wageningen Pers, Wageningen, The Netherlands, 1999.

Bloschl, G., M. Sivapalan, V. K. Gupta and K. J. Beven, (Preface to the special section of papers from the Fourth International Workshop on Scale Problems in Hydrology), Water Resour. Res. 33(12), 2881, 1997.

Burrough, P. A., Principles of GIS for Land Resource Assessment. Oxford: Clarendon Press, 1986.

Chrisman, N. R., What does 'GIS' mean?, Transactions in GIS, 3(2), 175-186, 1999.

Collin, J. J., Some aspects of desertification seen from the groundwater viewpoint. In Fantechi et al. (eds.), Desertification in a European Context: Physical and Socio-Economic Aspects. European Commission, DG12, Brussels, pag.111-121, 1995.

Crosbie, P., Object-oriented design of GIS: a new approach to environmental modelling. In M. F. Goodchild et al. (eds.), GIS and Environmental Modelling: Progress and Research Issues, 383386. GIS World Books, 1996.

Department of the Environment, Handling Geographic Information, Technical report, Her Majesty's Stationary Office, 1987.

Domenico, P. A. and F. W. Schwartz, Physical and Chemical Hydrogeology. John Wiley and Sons, New York, NY, 1990.

Dueker, K. and D. Kjerne, Multipurpose Cadastre: Terms and Definitions, Bethesda, MD, American Congress on Surveying and Mapping, 1989.

EC (European Communities), Council Directive concerning the protection of waters against pollution caused by nitrates from agricultural sources (91/676/EEC), OJ L 375, 31.12.1991; Bull. 12-1991, point 1.2.298, 1991.

EC (European Communities), Council Directive establishing a framework for Community action in the field of water policy. (COM(97)49 with subsequent amendments of the Commission and the Parliament; OJ C 343, 30.11.1999.

Ehlers, M., G. Edwards and Y. Bedard, Integration of remote sensing with geographic information systems: a necessary evolution, Photogrammetric Engineering and Remote Sensing, 55(11), 16191627, 1989.

Entekhabi, D., Recent advances in land-atmosphere interaction research. In: R. A. Pielke Sr. and R. M. Vogel (eds.) U.S. National Report to International Union of Geodesy and Geophysics 19911994: Contributions in Hydrology, 995-1003, American Geophysical Union, Washington, DC, 1995.

EPA, BASINS Version 2.0 User's Manual: Better Assessment Science Integrating Point and Nonpoint Sources. U.S. Environmental Protection Agency, Washington, DC 1998.

European Commission, A Strategic View of GIS Research and Technology Development for Europe, Technical report, EUR 18126, 1998. 
FAO (Food and Agriculture Organization of the United Nations), Groundwater pollution: Technology, economics and management. FAO Irr. And Drain. Paper 31, Rome, 1979.

FAO (Food and Agriculture Organization of the United Nations), Control of water pollution from agriculture. FAO Irr. And Drain. Paper 55, Rome, 1996.

Frind, E. O., Simulation of long-term transient density-dependent transport in groundwater, $A d v$. Water Resour., 5, 73-88, 1982.

Galeati, G., G. Gambolati and S. P. Neuman, Coupled and partially coupled Eulerian-Lagrangian model of freshwater-seawater mixing, Water Resour. Res., 28(1), 149-165, 1992.

Gallo, C., C. Paniconi and G. Gambolati, Comparison of solution approaches for the two-domain model of nonequilibrium transport in porous media, Adv. Water Resour., 19(4), 241-253, 1996.

Gambolati, G., C. Paniconi and M. Putti, Numerical modelling of contaminant transport in groundwater. In: Petruzzelli, D. and F. G. Helfferich (eds.) Migration and Fate of Pollutants in Soils and Subsoils. Springer-Verlag, Berlin. Volume 32 of NATO ASI Series G: Ecological Sciences, pp 381-410, 1993.

Gambolati, G., M. Putti and C. Paniconi, Projection methods for the finite element solution of the dual-porosity model in variably saturated porous media. In: Aral, M. M. (ed.) Advances in Groundwater Pollution Control and Remediation. Kluwer Academic, Dordrecht, Holland. Volume 9 of NATO ASI Series 2: Environment, pp 97-125, 1996.

Gambolati, G., M. Putti and C. Paniconi, Three-dimensional model of coupled density- dependent flow and miscible salt transport. In: Bear, J., A. H.-D. Cheng, S. Sorek, D. Ouazar and I. Herrera (eds.) Seawater Intrusion in Coastal Aquifers - Concepts, Methods and Practices. Kluwer Academic, Dordrecht, The Netherlands, pp 315-362, 1999.

Giardini, L. and C. Giupponi, Modelli agricoli e impatto ambientale. Franco Angeli, Milan, 1995.

Giupponi, C., Modelling agriculture and the environment: crop production and non-point source pollution. European J. Agronomy, 4, 403-412, 1995.

Giupponi, C., Environmental evaluation of alternative cropping systems with impact indices of pollution. European J. Agronomy, 8, 71-82, 1998.

Giupponi, C. and P. F. Ghetti, Valutazione dell'impatto sulla qualità delle acque di sistemi agricoli alternativi nel bacino scolante in Laguna di Venezia. VII Congresso Nazionale SitE, Napoli, 1996.

Giupponi, C. and P. Rosato, Simulating impacts of agricultural policy on nitrogen losses from a watershed in northern Italy. Environment International, 21, 577-582, 1995.

Giupponi, C. and P. Rosato, A farm multicriteria analysis model for the economic and environmental evaluation of agricultural land use. E. Beinat, P. Nijkamp (ed.), Multicriteria Evaluation in Land Use Management, Kluver Academic, 115-138, 1998.

Giupponi, C. and P. Rosato, Agricultural land use changes and water quality: a case study in the watershed of the Lagoon of Venice. Water Science and Technology. 39(3), 135-148, 1999.

Grayson, R. B., G. Blöschl, R. D. Barling and I. D. Moore, Process, scale and constraints to hydrological modelling in GIS. In HydroGIS 93: Application of Geographic Information Systems in Hydrology and Water Resources, 83-92. IAHS, Wien, 1993.

Grenon, M and M. Batisse, Futures for the Mediterranean Basin. The Blue Plan. Oxford University Press. New York, 1989.

Hassler, B., G. Lecca and C. Paniconi, Problems and features of saltwater upconing due to well pumping. CRS4 Technical Report, Cagliari, Italy, Dec 1999.

Henry, H. R., Effects of dispersion on salt encroachment in coastal aquifers. In: Sea Water in Coastal Aquifers. U.S. Geol. Surv. Water Supply Paper, No. 1613-C, pp 70-84, 1964.

Holden, P. W., Pesticides and Groundwater Quality. National Academy Press, Washington, D.C., 1986.

Huyakorn, P. S. and G. F. Pinder, Computational Methods in Subsurface Flow. Academic Press, New York, NY, 1983. 
Huyakorn, P. S., P. F. Andersen, J. W. Mercer and H. O. White, Saltwater intrusion in aquifers: Development and testing of a three-dimensional finite element model, Water Resour. Res., 23(2), 293-312, 1987.

Jenson, S. K. and J. O. Domingue, Extracting topographic structure from digital elevation data for geographic information system analysis, Photogrammetric Engineering and Remote Sensing, 54(11), 1593-1600, 1988.

King, J. L. and K. L. Kraemer, Models, facts, and the policy process: the political ecology of estimated truth. In M. F. Goodchild, B. O. Parks, and L. T. Steyaert (eds.), Environmental Modelling with GIS, 353-360. Oxford University Press, 1993.

Kinzelbach, W. and W. Schafer, Modelling and design of in-situ bioremediation measures. In: Groundwater Quality Management. IAHS Publ. No.220, 399-419, 1993.

Kite, G. W., Scaling of input data for macroscale hydrologic modelling, Water Resour. Res., 31(11), 2769-2781, 1995.

Kolditz, O., R. Ratke, H.-J. G. Diersch and W. Zielke, Coupled groundwater flow and transport: 1. Verification of variable density flow and transport models, Adv. Water Resour., 21(1), 27-46, 1998.

Kuniansky E. L. and R. A. Lowther, Finite-element mesh generation from mappable features, Int. J. Geographical Information Systems, 7(5), 395-405, 1993.

Leipnik, M. R., K. Kemp and H. A. Loaiciga, Implementation of GIS for water resources planning and management, Journal of Water Resource Planning and Management, 119, 184-205, 1993.

Livingstone, D. and J. Raper, Modelling environmental systems with GIS: Theoretical barriers to progress. In M. F. Worboys (ed.), Innovations in GIS, 229-240. Taylor \& Francis, London, 1994.

Maidment, D. R., GIS and hydrologic modelling. In: M. F. Goodchild, B. O. Parks and L. T. Steyaert (eds.) Environmental Modelling with GIS. Oxford University Press, New York, NY, pp 147-167, 1993.

Maidment, D. R., Environmental modelling within GIS. In M. F. Goodchild et al. (eds.), GIS and Environmental Modelling: Progress and Research Issues, 315-323. GIS World Books, 1996.

Mangold, D. C. and C. F. Tsang, A summary of subsurface hydrological and hydrochemical models, Rev. Geophys., 29(1), 51-79, 1991.

Merchant, J. W., GIS-based groundwater pollution hazard assessment: A critical review of the DRASTIC model, Photogrammetric Engineering and Remote Sensing, 60(9), 1117-1127, 1994.

Miller, M. R., P. L. Brown, J. J. Donovan, R. N. Bergatino, J. L. Sonderegger and F. A. Schmidt, Saline seep development in the North American Great Plains - Hydrological aspects. J.W. Holmes and T Talsma (eds.) Land and stream salinity. Elsevier, Amsterdam, 115-141, 1981.

Moore, I. D., A. K. Turner, J. P. Wilson, S. K. Jenson and L. E. Band, GIS and land-surfacesubsurface process modelling. In: Goodchild, M. F., B. O. Parks and L. T. Steyaert (eds.) Environmental Modelling with GIS. Oxford University Press, New York, NY, pp 196-230, 1993.

Novotny V. and Olem H., Water quality. Prevention, identification and management of Diffuse pollution. New York (USA). Van Nostrand Reinold. 1050 p., 1994.

Nyerges, T. L., Understanding the scope of GIS: its relationship to environmental modelling. In M. F. Worboys (ed.), Innovations in GIS, 75-93. Taylor \& Francis, 1994.

OECD (Organisation for Economic Cooperation and Development), Environmental Indicators OECD Core Set. OECD, Paris, 1994.

OGC Technical Committee, The OpenGIS Guide, The OpenGIS Consortium, Wayland, MA, 1998.

Paniconi, C. and M. Putti, A comparison of Picard and Newton iteration in the numerical solution of multidimensional variably saturated flow problems, Water Resour. Res., 30(12), 3357-3374, 1994.

Paniconi, C., S. Kleinfeldt, J. Deckmyn and A. Giacomelli, Integrating GIS and data visualization tools for distributed hydrologic modelling, Transactions in GIS, 3(2), 97-118, 1999.

Parker, J. C., Multiphase flow and transport in porous media, Rev. Geophys., 27(3), 311-328, 1989. 
Peirce, M., Computer-based models in integrated environmental assessment. Technical Report AEAT-1987, AEA Technology, 1998.

Perez-Trejo, F., Desertification and land degradation in the European Mediterranean. EPOCH Programme, EC-DG12, EUR 14850 EN, 1992.

Philip, J. R., Theory of infiltration, Adv. Hydrosci., 5, 215-296, 1969.

Putti, M. and C. Paniconi, Picard and Newton linearization for the coupled model of saltwater intrusion in aquifers, Adv. Water Resour., 18(3), 159-170, 1995.

Raper, J. and D. Livingstone, High-level coupling of GIS and environmental process modelling. In M. F. Goodchild et al. (eds.), GIS and Environmental Modelling: Progress and Research Issues, 387-390. GIS World Books, 1996.

Renard, K. G., W. J. Rawls and M. M. Fogel, Currently available models. In C. T. Haan, H. P. Johnson and D. L. Brakensiek (eds.), Hydrologic Modelling of Small Watersheds, 507-522, Amer. Soc. Agr. Eng., St. Joseph, MI, 1982.

Richards, J. A., Remote Sensing Digital Image Analysis, An Introduction. Springler-Verlag, New York, 1986.

Ritchie, J. T., Using crop models as a decision support system to reduce nitrate leaching. In: F. M. D'Itri and L. G. Wolfson (eds.) Rural Groundwater Contamination, Lewis Publisher, 179-192, 1987.

Schincariol, R. A., F. W. Schwartz and C. A. Mendoza, On the generation of instabilities in variable density flow, Water Resour. Res., 30(4), 913-927, 1994.

Ségol, G., Classic Groundwater Simulations: Proving and Improving Numerical Models. PTR Prentice Hall, Englewood Cliffs, NJ, 1993.

Sherif, M. M. and V. P. Singh, Saltwater intrusion. In: Singh, V. P. (ed.) Hydrology of Disasters. Kluwer Academic, Dordrecht, Holland, pp 269-316, 1996.

Simmons, C. T., K. A. Narayan and R. A. Wooding, On a test case for density-dependent groundwater flow and solute transport models: The salt lake problem, Water Resour. Res., 35(12), 3607-3620, 1999.

Simonovic, S. P., Risk in sustainable water resources management. In: Sustainability of Water Resources Under Increasing Uncertainty, IAHS Publ. 240, 3-17, 1997.

Smith, R. A., G. E. Schwarz and R. B. Alexander, Regional interpretation of water-quality monitoring data, Water Resour. Res., 33(12), 2781-2798, 1997.

Star, J. and J. Estes, Geographic Information Systems: An Introduction. Prentice Hall, Englewood Cliffs, NJ, 1990.

Suarez, D. L., Impacts of agricultural practices on groundwater salinity. Agriculture, Ecosystems and Environment, 26, 215-227, 1989.

Taigbenu, A. E., J. A. Liggett and A. H.-D. Cheng, Boundary integral solution to seawater intrusion into coastal aquifers, Water Resour. Res., 20(8), 1150-1158, 1984.

Umali, D. L., Irrigation induced salinity - A growing problem for development and the environment. World Bank Technical Paper, No.215, 1993.

UNITAR (UNITED NATIONS INSTITUTE FOR TRAINING AND RESEARCH), GIS and decision making. UNITAR, Geneva, Switzerland, 128 pp, 1995

United Nations Environment Program (UNEP), A survey of spatial data handling technologies 1997, environmental and assessment technical report 13. Technical report, United Nations Environment Programme, Global Resources Information Database, Sioux Falls, SD, USA, 1999. Online. Available: http://grid2.cr.usgs.gov/survey/97survey/survey.html.

van Genuchten, M. T. and D. R. Nielsen, On describing and predicting the hydraulic properties of unsaturated soils, Ann. Geophys, 3(5), 615-628, 1985.

van Genuchten, M. T. and J. Simunek, Evaluation of pollutant transport in the unsaturated zone. In: Rijtema, P. E. and V. Elias (eds.) Regional Approaches to Water Pollution in the Environment. Kluwer Academic, Dordrecht, Holland, pp 139-172, 1996. 
van Keulen, H. and J. Wolf, Modelling of agricultural production: weather, soils and crops. Pudoc, Wageningen (NL), 1986.

Voss, C. I. and W. R. Souza, Variable density flow and solute transport simulation of regional aquifers containing a narrow freshwater-saltwater transition zone, Water Resour. Res., 23(10), 1851-1866, 1987.

Welsh, D. J., Riparian forest buffers. Function and design for protection and enhancement of water resources. USDA, Radnor, PA, 1991.

Wilson, J. P., GIS-based land surface/subsurface modelling: New potential for new models?, In: Proceedings Third International NCGIA Conference on Integrating GIS and Environmental Modelling, CD-ROM, NCGIA, Santa Barbara, CA, 1996.

Yurdisef, M. A. and D. G. Jamieson, Development of a water resources planning model which includes environmental considerations. In: Sustainability of Water Resources Under Increasing Uncertainty, IAHS Publ. 240, 419-425, 1997.

Zalidis, G., Management of river water for irrigation to mitigate soil salinisation on a coastal watershed. J. Environmental Management, 54, 161-167, 1998.

Zienkiewicz, O. C., The Finite Element Method. McGraw-Hill, New York, NY, 1986.

Zimmerman, D. A., G. de Marsily, C. A. Gotway, M. G. Marietta, C. L. Axness, R. L. Beauheim, R. L. Bras, J. Carrera, G. Dagan, P. B. Davies, D. P. Gallegos, A. Galli, J. Gomez-Hernandez, P. Grindrod, A. L. Gutjahr, P. K. Kitanidis, A. M. Lavenue, D. McLaughlin, S. P. Neuman, B. S. RamaRao, C. Ravenne and Y. Rubin, A comparison of seven geostatistically based inverse approaches to estimate transmissivities for modelling advective transport by groundwater flow, Water Resour. Res. 34(6), 1373-1413, 1998. 
Figure 1: The hydrological cycle in agro-ecosystems.

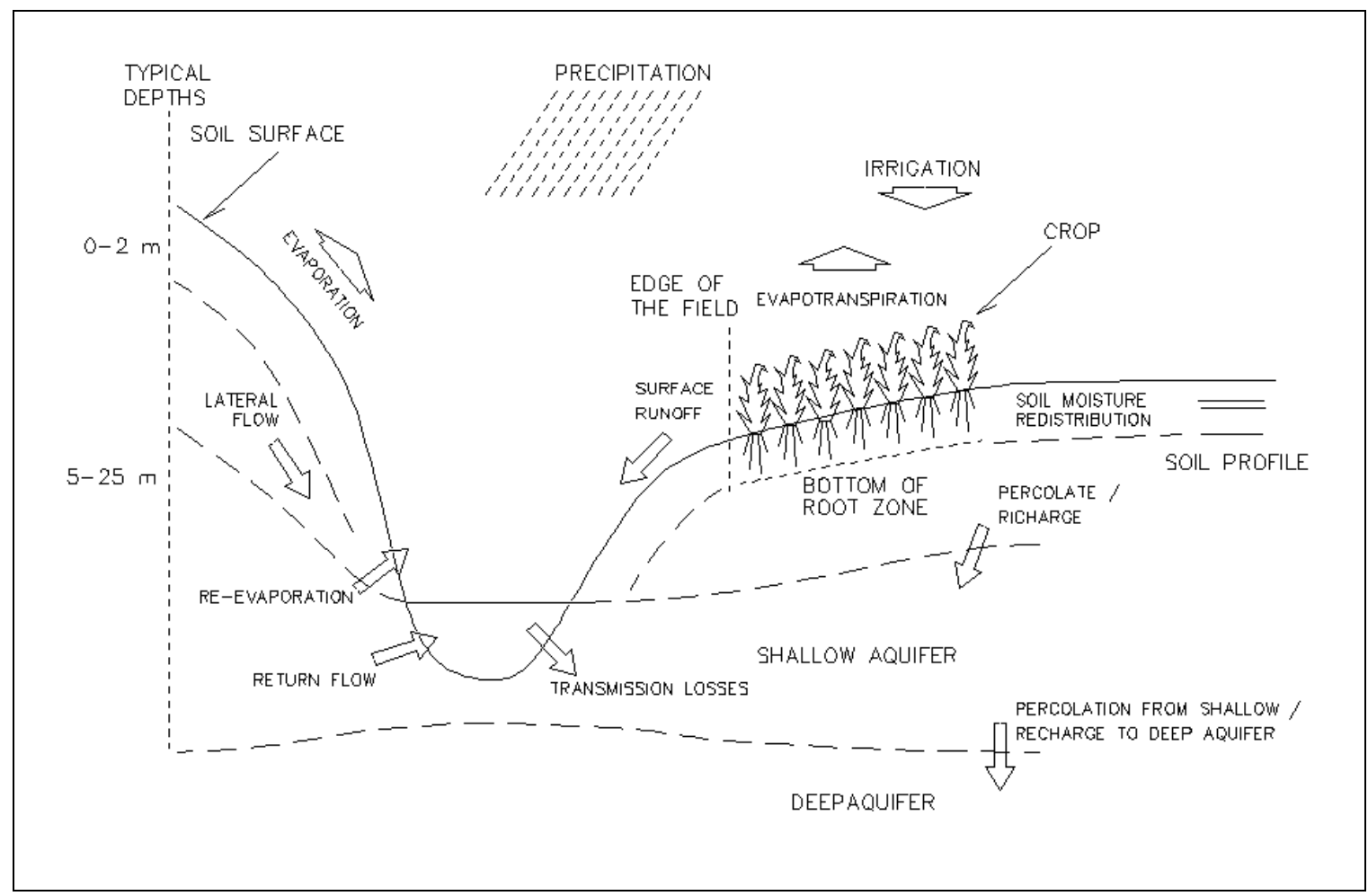

Figure 2: The subsurface as buffer and filter: propagation and attenuation of a rainfall signal on its downward journey through a porous medium (adapted from Entekhabi, 1995).

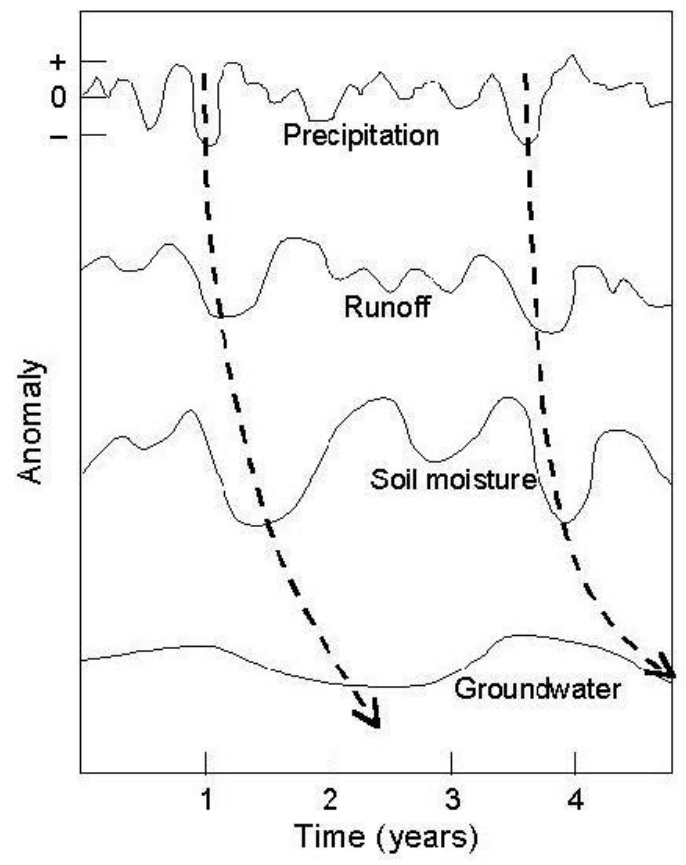


Figure 3: Hysteresis and irreversibility in groundwater exploitation: groundwater upconing is compounded via repeated cycles of pumping and active recovery, and the saltwater interface inexorably rises to reach the pumping well, situated at $20 \mathrm{~m}$ from the initial position of the interface (from Hassler et al., 1999).

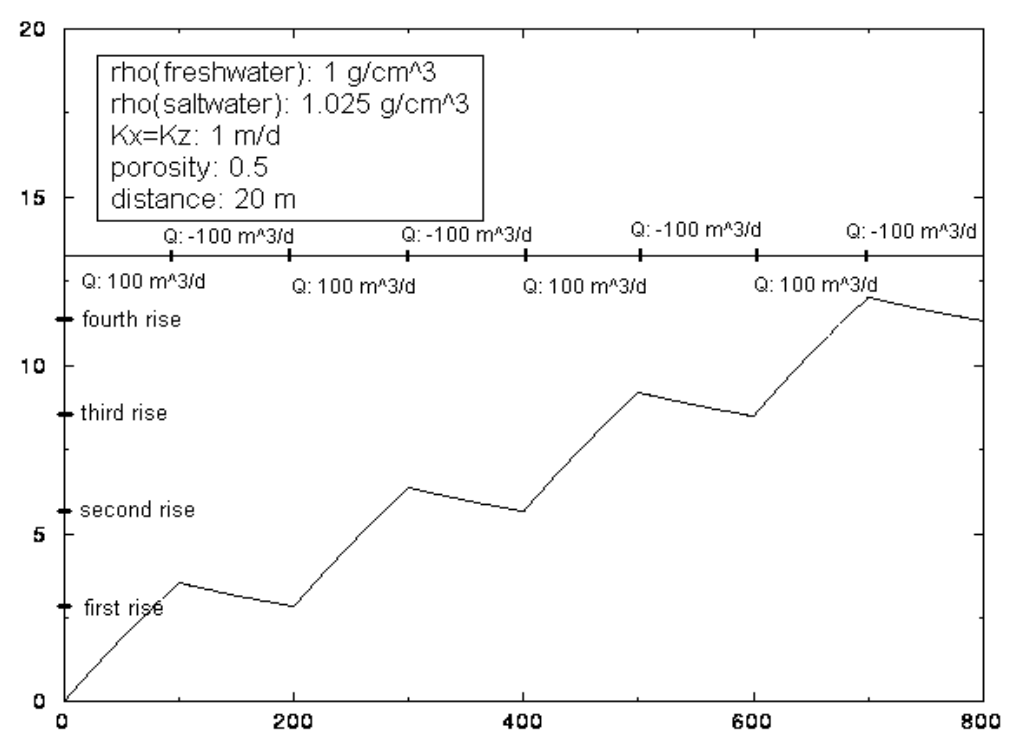

Figure 4: Schematic representation of seawater intrusion in a coastal aquifer (adapted from Sherif and Singh, 1996).

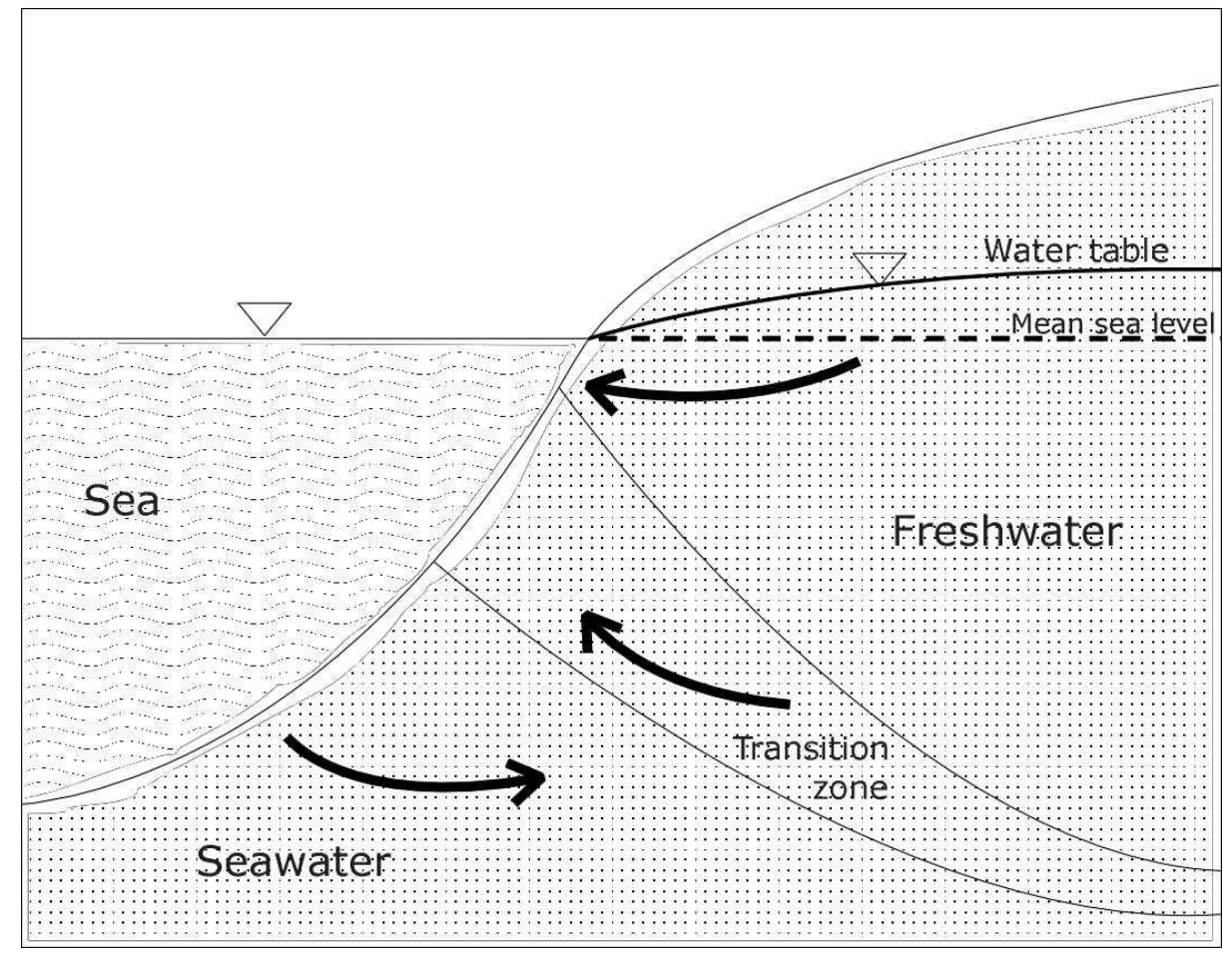


Table 1: Model input, output, and calibration data for the case of seawater intrusion.

\begin{tabular}{|c|c|}
\hline Hydrometeorological data (input) & $\begin{array}{l}\text { (a) topographic \& geomorphologic data (channel networks, subcatchment units, etc) } \\
\text { (b) soil characteristics and hydraulic functions } \\
\text { (c) rainfall/evaporation rates } \\
\text { (d) overland runoff data }\end{array}$ \\
\hline Soil and land use data (input) & $\begin{array}{l}\text { (e) land use and agricultural data (e.g., crop salt tolerances, root uptake rates) } \\
\text { (f) irrigation data (application rates and salinity levels) }\end{array}$ \\
\hline Hydrogeological data (input) & $\begin{array}{l}\text { (g) geological data (statigraphy, characteristics of the aquifers, aquitards, lenses, } \\
\text { fractures, faults) } \\
\text { (h) saline deposits and formations } \\
\text { (i) porosity } \\
\text { (j) hydraulic conductivity } \\
\text { (k) aquifer storativity } \\
\text { (l) dispersion (dispersivity coefficients) } \\
\text { (m) density ratio }\end{array}$ \\
\hline Other data (input) & (n) any other information concerning hydro/geo/pedo-logic heterogeneities \\
\hline Aquifer use (input) & $\begin{array}{l}\text { (o) location of pumping wells } \\
\text { (p) pumping rates } \\
\text { (q) aquifer recharge data }\end{array}$ \\
\hline $\begin{array}{l}\text { Monitoring data (model input, calibration, } \\
\text { updating, and verification) }\end{array}$ & $\begin{array}{l}\text { (r) streamflow rates and quality } \\
\text { (s) piezometric data including salinity levels } \\
\text { (t) water table levels }\end{array}$ \\
\hline Model output & $\begin{array}{l}\text { (u) salt concentrations } \\
\text { (v) saltwater/freshwater interface (position, "sharpness", dynamics) } \\
\text { (w) soil moisture content } \\
\text { (x) groundwater pressure heads } \\
\text { (y) groundwater pressure gradients } \\
\text { (z) groundwater velocities }\end{array}$ \\
\hline
\end{tabular}

Table 2. Model input, output and calibration data (see Table 1) relevant for addressing the 7 policy issues or actions described in the text. "Other" refers to non-process or scientific data (e.g., socio-economic data).

\begin{tabular}{|c|c|c|c|c|c|c|c|c|c|c|c|c|c|c|c|c|c|c|c|c|c|c|c|c|c|c|c|}
\hline \multirow{2}{*}{$\begin{array}{l}\text { POLICY } \\
\text { ISSUE }\end{array}$} & \multicolumn{17}{|c|}{ INPUT } & \multicolumn{3}{|c|}{ CALIB. } & \multicolumn{6}{|c|}{ OUTPUT } & \multirow[t]{2}{*}{ OTHER } \\
\hline & a & $\mathrm{b}$ & c & d & e & $f$ & $g$ & $\mathrm{~h}$ & i & j & k & 1 & $\mathrm{~m}$ & $n$ & 0 & p & q & $r$ & s & $\mathrm{t}$ & $\mathrm{u}$ & $\mathrm{v}$ & w & $x$ & $y$ & $z$ & \\
\hline 1 & & & & & • & & & & & & & & & • & & & & & • & & $\bullet$ & & & & & & • \\
\hline 2 & & & $\bullet$ & & & & & & & $\bullet$ & & $\bullet$ & & & & $\bullet$ & & & & & & $\bullet$ & & & $\bullet$ & $\bullet$ & \\
\hline 3 & $\bullet$ & $\bullet$ & & $\bullet$ & $\bullet$ & $\bullet$ & & & & & & & & $\bullet$ & & & & & & & $\bullet$ & & $\bullet$ & $\bullet$ & & & $\bullet$ \\
\hline 4 & & & & & & & $\bullet$ & & & $\bullet$ & • & & & & & & $\bullet$ & & $\bullet$ & $\bullet$ & & $\bullet$ & & $\bullet$ & $\bullet$ & & $\bullet$ \\
\hline 5 & • & & $\bullet$ & & & & • & $\bullet$ & $\bullet$ & • & • & • & $\bullet$ & $\bullet$ & $\bullet$ & $\bullet$ & & & & & & & & $\bullet$ & $\bullet$ & $\bullet$ & • \\
\hline 6 & & & & & & $\bullet$ & $\bullet$ & $\bullet$ & & & & & $\bullet$ & & $\bullet$ & $\bullet$ & $\bullet$ & $\bullet$ & $\bullet$ & & - & $\bullet$ & & & $\bullet$ & - & \\
\hline 7 & & & & & & 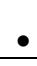 & & & & & & & & $\bullet$ & • & $\bullet$ & & • & $\bullet$ & $\bullet$ & $\bullet$ & & & $\bullet$ & & & $\bullet$ \\
\hline
\end{tabular}


I The model of Smith et al. (1997) takes the form:

$$
\begin{gathered}
L_{i}=\sum_{n=1}^{N} S_{n, i} \\
S_{n, i}=\sum_{j \in J(i)} s_{n, j} D_{n}\left(Z_{j}\right) K\left(T_{i, j}\right) \\
D_{n}\left(Z_{j}\right)=\beta_{n} \exp \left(-\alpha^{T} Z_{j}\right) \\
K\left(T_{i, j}\right)=\exp \left(-\delta^{T} T_{i, j}\right)
\end{gathered}
$$

where $L_{i}$ is the contaminant transport in stream reach $i$ and $S_{n, i}$ is the contaminant load from source $n$ delivered to reach $i$ from all reaches in subbasin $J(i)$. The $N$ sources for each stream reach $i$ include both point and nonpoint contaminants, and are delivered to the outlet in a two-stage process: land surface to channel network and channel network to outlet at reach $i$. Thus the second equation contains the contribution to the contaminant mass from source $n, s_{n, j}$, from each reach $j$ of the subbasin, the proportion $D_{n}$ of this mass that is delivered as a function of land surface characteristics $Z_{j}$, and the proportion $K$ transported as a function of channel characteristics $T_{i, j}$. The functional form of the two stages of the delivery process is empirically parameterised as the third and fourth equations, where $\beta_{n}$ accounts for sources, $\alpha$ is a vector of delivery coefficients associated with land surface characteristics, and $\delta$ is a vector of decay coefficients associated with channel or flow path characteristics. In a demonstration of the interpretive uses of the model, two applications are described. The first is to estimate the proportion of watersheds in the U.S. that meet national clean water standards (for phosphorus, outflow TP concentrations less than $0.1 \mathrm{mg} / \mathrm{l}$ ). The second application is to classify watersheds on a region-by-region basis according to predicted total nitrogen yield thresholds of TN $<500 \mathrm{~kg} / \mathrm{kg}^{2} / \mathrm{yr}$ and $\mathrm{TN}<1000 \mathrm{~kg} / \mathrm{kg}^{2} / \mathrm{yr}$.

${ }^{\text {II }}$ Richards' equation may be written as (Philip, 1969)

$$
\sigma \frac{\partial \psi}{\partial t}=\nabla \cdot\left[K_{s} K_{r}\left(\nabla \psi+\eta_{z}\right)\right]+q
$$

where $\sigma(\psi)$ is the general storage term or overall storage coefficient, $\psi$ is the pressure head, $t$ is time, $\nabla$ is the gradient operator, $K_{s}$ is the saturated hydraulic conductivity tensor, $K_{r}(\psi)$ is the relative hydraulic conductivity, $\eta_{z}$ is a vector equal to zero in its $x$ and $y$ components and 1 in its $z$ component, $z$ is the vertical coordinate directed upward, and $q$ is the injected (positive)/extracted (negative) volumetric flow rate. The general storage term can be expressed as

$$
\sigma=S_{w} S_{s}+\phi \frac{d S_{w}}{d \psi}
$$

where $S_{w}=\theta / \theta_{s}, \theta$ is the volumetric moisture content, $\theta_{s}$ is the saturated moisture content (generally equal to the porosity $\phi$ ), and $S_{s}$ is the specific storage.

III The equation describing the transport of a reactive contaminant in variably saturated porous media may be written as (Bear, 1979; Huyakorn and Pinder, 1983; Gambolati et al., 1993)

$$
\phi S_{w} R_{d}\left(\frac{\partial c}{\partial t}+\lambda c\right)=\nabla \cdot(D \nabla c)-v \cdot \nabla c+q\left(c^{*}-c\right)+f
$$

where $R_{d}$ is the retardation factor representing adsorption, $c$ is the concentration of the solute, $\lambda$ is the decay constant, $D$ is the dispersion tensor, $v$ is the Darcy velocity vector, $c^{*}$ is the solute concentration in the injected/extracted fluid, and $f$ is the volumetric rate of injected (positive)/extracted (negative) solute that does not affect the velocity field. The dispersion tensor $D=\phi S_{w} D^{\sim}$, where $D^{\sim}$ is defined as in Bear (1979), is given by

$$
D_{i j}=\phi S_{w} \tilde{D}_{i j}=\alpha_{T}|v| \delta_{i j}+\left(\alpha_{L}-\alpha_{T}\right) \frac{v_{i} v_{j}}{|v|}+\phi S_{w} D_{o} \tau \delta_{i j} \quad i, j=x, y, z
$$

where $\alpha_{L}$ and $\alpha_{T}$ are the longitudinal and transverse dispersivity coefficients, respectively, $|v|$ is the magnitude of the velocity vector, $\delta_{i j}$ is the Kronecker delta, $D_{o}$ is the molecular diffusion coefficient, and $\tau$ is the tortuosity $(\tau=1$ is usually assumed).

IV The coupled model of density-dependent variably saturated flow and miscible salt transport can be expressed as (Gambolati et al., 1999)

$$
\begin{gathered}
\sigma \frac{\partial \psi}{\partial t}=\nabla \cdot\left[K_{s} \frac{1+\varepsilon c}{1+\varepsilon^{\prime} c} K_{r}\left(\nabla \psi+(1+\varepsilon c) \eta_{z}\right]-\phi S_{w} \varepsilon \frac{\partial c}{\partial t}+\frac{\rho}{\rho_{o}} q\right. \\
v=-K_{s} \frac{1+\varepsilon c}{1+\varepsilon^{\prime} c} K_{r}\left(\nabla \psi+(1+\varepsilon c) \eta_{z}\right) \\
\phi \frac{\partial S_{w} c}{\partial t}=\nabla \cdot(D \nabla c)-\nabla \cdot(c v)+q c^{*}+f
\end{gathered}
$$


where all variables are as previously defined except that now the general storage term $\sigma$ is a function of both pressure head and concentration.

$\mathrm{v}$ Given the intrinsic multidisciplinarity with which GIS has evolved, several definitions, stemming from different perspectives, have been proposed. Generally, we may encounter definitions emphasising a functional flow (e.g., “...a system for capturing, storing, checking, manipulating, analysing and displaying data which are spatially referenced to the Earth" (Department of the Environment, 1987)), those following a "content approach" focusing on data (e.g., "an information system that is designed to work with data referenced by spatial or geographic coordinates. In other words, a GIS is both a database system with specific capabilities for spatially-referenced data, as well as a set of operations for working with the data" (Star and Estes, 1990)), and, lastly, those adding to data and tools a "human resources" component (e.g., "...a system of hardware, software, data, people, organisations, and institutional arrangements for collecting, storing, analysing, and disseminating information about areas of the Earth" (Dueker and Kjerne, 1989), or "...organised activity by which people measure and represent geographic phenomena then transform these representations into other forms while interacting with social structures" (Chrisman, 1999)). 